NBER WORKING PAPER SERIES

\title{
MARRIAGE INSTITUTIONS AND SIBLING COMPETITION: EVIDENCE FROM SOUTH ASIA
}

\author{
Tom Vog1 \\ Working Paper 18319 \\ http://www.nber.org/papers/w18319 \\ NATIONAL BUREAU OF ECONOMIC RESEARCH \\ 1050 Massachusetts Avenue \\ Cambridge, MA 02138 \\ August 2012
}

An earlier draft of this paper circulated under the title, "Sisters, Schooling, and Spousal Search: Evidence from South Asia." I am grateful to Erica Field, Michael Kremer, and especially David Cutler, Claudia Goldin, and Lawrence Katz for their guidance throughout this research project. I thank Ruchir Agarwal, Anne Case, Amitabh Chandra, Joyce Chen, Tom Cunningham, Supreet Kaur, Michal Kolesar, Ed Glaeser, Seema Jayachandran, Kyle Meng, Sendhil Mullainathan, Daniele Paserman, Nancy Qian, Monica Singhal, and seminar participants at BU, Harvard, Princeton, RAND, Yale, UCLA, UT Austin, and the World Bank for helpful comments and suggestions. Bishnu Thapa provided excellent research assistance and sage insights into Nepali society. This research was supported by the Multidisciplinary Program on Inequality and Social Policy (NSF IGERT Grant 0333403) and the NBER Aging Program (NIA Grant T32-AG000186). The views expressed herein are those of the author and do not necessarily reflect the views of the National Bureau of Economic Research.

NBER working papers are circulated for discussion and comment purposes. They have not been peerreviewed or been subject to the review by the NBER Board of Directors that accompanies official NBER publications.

(c) 2012 by Tom Vogl. All rights reserved. Short sections of text, not to exceed two paragraphs, may be quoted without explicit permission provided that full credit, including $($ ) notice, is given to the source. 
Marriage Institutions and Sibling Competition: Evidence from South Asia

Tom Vogl

NBER Working Paper No. 18319

August 2012

JEL No. I25,J12,O12

\begin{abstract}
$\underline{\text { ABSTRACT }}$
Using data from South Asia, this paper examines how arranged marriage cultivates rivalry among sisters. During marriage search, parents with multiple daughters reduce the reservation quality for an older daughter's groom, rushing her marriage to allow sufficient time to marry off her younger sisters. Relative to younger brothers, younger sisters increase a girl's marriage risk; relative to younger singleton sisters, younger twin sisters have the same effect. These effects intensify in marriage markets with lower sex ratios or greater parental involvement in marriage arrangements. In contrast, older sisters delay a girl's marriage. Because girls leave school when they marry and face limited earnings opportunities when they reach adulthood, the number of sisters has well-being consequences over the lifecycle. Younger sisters cause earlier school-leaving, lower literacy, a match to a husband with less education and a less-skilled occupation, and (marginally) lower adult economic status. Data from a broader set of countries indicate that these cross-sister pressures on marriage age are common throughout the developing world, although the schooling costs vary by setting.
\end{abstract}

Tom Vogl

Department of Economics

Princeton University

363 Wallace Hall

Princeton, NJ 08544

and NBER

tvogl@princeton.edu 


\section{Introduction}

Economic, social, and cultural change occur unevenly, with some behaviors and institutions lagging behind technological progress. Social scientists have long been interested in how these slowlyevolving traditions interact with the process of development (e.g., Weber 1905; Grief 1994; Guiso et al. 2006). One such tradition is arranged marriage. While this tradition has gradually given way to love marriage in some societies over the past millennium, it remains prevalent in many parts of the world (Goode 1970; Goody 1983). For example, among Indian women born in the 1950s, 1960s, and 1970s, only 5 percent report having arranged their marriages independently of their families (Desai and Andrist 2010). This paper uses data from South Asia to study how the family's continued influence over marriage arrangements creates tradeoffs among siblings, such that one sibling's presence in the family affects another sibling's marriage and human capital outcomes. The interaction of this tradition with recent expansions in mobility and educational opportunity appears to magnify these tradeoffs.

Competition among siblings has received much attention for its potential to have a lasting impact on the outcomes of children, but the typical economic treatment of this issue places little emphasis on institutions like arranged marriage. In the standard framework, siblings compete for limited resources within the household, so that an increase in the number of children decreases average child investment. ${ }^{1}$ But sibling rivalry also occurs in arenas that are not fully captured by a conventional budget constraint. For instance, siblings of the same gender participate in the same marriage market, sharing a pool of potential spouses. In some ways, they are like any other participants on the same side of the market, but their membership in the same family introduces special constraints on their marriages. Indeed, these constraints are particularly severe in societies with arranged marriage, where for a variety of reasons parents seek to marry children of the same sex in order of birth. When search for a suitable spouse takes time, this practice implies that samesex siblings constrain each other's marriage arrangements. A girl's presence in the family leads her parents to hurry the marriage arrangements of her older sisters and delay those of her younger sisters, both at the expense of groom quality. The logic is similar for boys but probably more acute

\footnotetext{
${ }^{1}$ The classic model of the tradeoff between child quality and quantity is due to Becker and Lewis (1973). Early evidence of the negative association between childhood family size and adult outcomes can be found in Leibowitz (1974) and Blake (1983). Despite this association, Black et al. (2005) and Angrist et al. (2010) find no evidence in data from Norway and Israel that an exogenous increase in the number of younger siblings affects adult outcomes. But Li et al. (2008) and Rosenzweig and Zhang (2009) estimate negative family size effects on schooling outcomes in China.
} 
for girls, who in many parts of the world (including South Asia) leave school if they marry young (Field and Ambrus 2008). Since women's economic status depends heavily on age at marriage, schooling, and spousal attributes, the impact of these sibling effects may be felt well into adulthood.

This paper focuses on measuring that impact, but it begins by describing the practice of marrying daughters in order of birth and by outlining a simple marriage search framework to clarify how this practice leads to cross-sibling effects. The search framework predicts that the presence of older sisters delays the marriages of their younger sisters; that the presence of younger sisters hastens the marriages of their older sisters; and that the presence of any sisters reduces expected groom quality. Using data primarily from the Demographic and Health Surveys (DHS), the paper then analyzes sister effects in South Asia's four largest countries, which together comprise more than a fifth of the world's population. Much of the analysis centers on a simple natural experiment within the family. If a girl has at least $x$ younger siblings, then in the absence of sex selection, one can treat the gender of her $x^{\text {th }}$-younger sibling as exogenous. ${ }^{2}$ A comparison of girls with next-born brothers and sisters thus identifies the effect of the next-born sibling's gender. The analysis has two parts. The first uses data from Bangladesh, India, Nepal, and Pakistan that indicate whether a girl has left her natal home, with no information on her outcomes afterward. Home-leaving is tantamount to marriage for South Asian women, so parental coresidence serves as a useful proxy for never-marriage. The second part of the analysis uses data from Nepal with more extensive information on adult outcomes.

Across all four countries, teenage girls with next-youngest sisters are roughly 3 percentage points more likely to have left their natal homes than their counterparts with next-youngest brothers. The effects are stronger in rural areas, where marriage markets are thinner; in areas with more parental involvement in marriage arrangements, where cross-sister constraints would be expected to be stronger; and in marriage markets with low ratios of marriageable men to marriageable women, consistent with the idea that a scarcity of grooms intensifies parents' fear that they will fail to find a husband for their younger daughter. A complementary analysis of twin births, though underpowered due to the rarity of twins, gives suggestive evidence that younger brothers (the comparison group in the main analysis) serve mainly as buffers between sisters. Relative to a singleton female birth, the birth of twin girls raises home-leaving among older sisters, whereas

\footnotetext{
${ }^{2}$ The paper takes seriously the possibility that the gender of the $x^{\text {th }}$-younger sibling is endogenous. As Section 5.1 .1 discusses, the data do not show consistent evidence of sex selection across the four countries.
} 
twin boys have no effect relative to a singleton boy. Also, as the search framework predicts, girls with next-oldest sisters marry later than those with next-oldest brothers. Because endogenous fertility confounds comparisons based on the sex composition of older siblings, the paper assesses the extent of selection bias using both Heckman's (1974) selection correction model and Lee's (2009) non-parametric bounds estimator. ${ }^{3}$ Both methods give results consistent with the hypothesis that the presence of an older sister causes a girl to leave home later, although the 95 percent confidence interval of the bounds estimator includes zero. The data thus suggest that older and younger sisters have opposite effects on home-leaving risk.

These sister effects on home-leaving have lasting consequences. To examine these consequences, I analyze DHS data from Nepal in which adult women report all of their siblings ever born. Consistent with the results on home-leaving, women with younger sisters marry earlier and initiate childbearing half a year earlier than women with younger brothers. The earlier transition to married life comes at the expense of human capital and spousal quality. Next-youngest sisters cause lower school attendance among marriage-age teenagers, as well as lower educational attainment and literacy among adult women. The effects on school attendance among current teenagers are especially large: 7 percentage points, or nearly 40 percent of the gender gap in teen school attendance. Furthermore, compared to women with next-youngest brothers, women with next-youngest sisters have husbands with less education and lower skill occupations, and they live in marginally poorer households.

How siblings affect adult outcomes is an enduring question in the social sciences, so the results are of interest independent of the mechanism mediating them. But collectively, the results suggest a prominent role for marriage search and are inconsistent with leading alternative theories of the effects of sibling composition on adult wellbeing. In this respect, the queuing of girls to leave the household is perhaps the most distinguishing result. Neither models in which the gender of a child is a generic wealth shock, nor models in which parents substitute resources from girls to boys, nor models of son-biased fertility stopping behavior, nor models of the demand for male and female labor in the household predict on their own that older sisters have the opposite effect of younger sisters. Many of these theories also predict effects of sibling sex composition in earlier childhood, which the data do not show. After these explanations, one prominent alternative re-

\footnotetext{
${ }^{3}$ Both methods assume monotonicity in the effect of treatment on selection. I discuss the appropriateness of this assumption below.
} 
mains, also rooted in the marriage market. This alternative theory posits that liquidity-constrained families adjust their daughters' marriage ages because they cannot afford to pay two dowries in close succession. But the data indicate that the effects of younger sisters on marriage risk are if anything weaker in regions known to have large and burdensome dowries than in regions where dowries are rare and small. Sister effects on age at marriage are also evident in societies outside South Asia, some of which exchange brideprice rather than dowry. The interaction of marriage costs with liquidity constraints is thus unlikely to explain the results.

Because the results appear to be driven by the number of sisters rather than the number of brothers, they have implications for the effects of both sibling sex composition and family size. Much of my empirical work makes comparisons based on the sex of the next-youngest sibling, which speaks most directly to the literature on sibling sex composition. A few papers in this literature have considered the role of patrilineal and matrilineal inheritance norms (see Fafchamps and Quisumbing 2007), but on the whole, the economics literature has tended to emphasize more generic theories of intra-household resource distribution, without regard to specific institutions like arranged marriage. ${ }^{4}$ In an early paper on the topic, Parish and Willis (1993) note that oldest daughters in Taiwanese families marry and leave school early, which they interpret through the lens of credit constraints. ${ }^{5}$ Relative to their paper and others in the earlier literature, this paper makes a contribution by paying close attention to which causal parameters within the family are identifiable in observational data.

Because an increase in family size on average increases the number of sisters, the paper also relates to research on the effects of family size. Recent results from Norway suggest that although an increase in the number of younger siblings does not affect adult outcomes, an increase in the number of older siblings (i.e., an increase in birth order) reduces educational attainment and adult economic status (Black et al. 2005). These results stand in contrast to South Asia, where having older sisters allows a girl to remain in school, whereas having younger sisters forces her to leave. The mechanisms underlying the Norwegian findings remain unknown, but these differences remind us that varying constraints on household decisions lead to varying forms of sibling competition.

\footnotetext{
${ }^{4}$ The literature on the effects of sibling sex composition has varied results; see Steelman et al. (2001) for a review. Edmonds (2006) studies various aspects of sibling differences in child labor in Nepal. Garg and Morduch (1997) and Morduch (2000) find mixed evidence that African girls with a greater share of female siblings display better health and education outcomes. In work on the United States, Butcher and Case (1994) report that women with brothers attain more education than women with sisters, although Kaestner (1997) finds no such evidence in later birth cohorts.

${ }^{5}$ In related work, Chen et al. (2010) do not find that the sex of a Taiwanese girl's twin affects her health or education.
} 
Even so, given the prevalence of arranged marriage in many parts of the world, the crosssibling marriage pressures documented in South Asia are likely to carry to other settings. Indeed, the penultimate section of the paper shows that sister effects on age at marriage are evident across much of the developing world, although they are much smaller in world regions with less arranged marriage. ${ }^{6}$ Meanwhile, the effects on schooling surface only in societies where marriage occurs sufficiently early, and school-leaving occurs sufficiently late. In this sense, the results contribute to the research effort towards understanding the ramifications of various marriage institutions, especially during times of social, economic, and demographic change (e.g., Edlund 1999; Edlund and Lagerlöf 2006; Tertilt 2006; Anderson 2007; Jacoby and Mansuri 2010). More broadly, they relate to the recent literature on how variation in the cultural importance of family ties shapes both individual and aggregate economic outcomes (Bertrand and Schoar 2006; Alesina and Giuliano 2010).

\section{Sex-Specific Birth Order and Marriage: Background}

Historical texts from both inside and outside South Asia contain many references to the practice of marrying daughters in strict order of birth. In the Hebrew Bible, Laban deceives Jacob into marrying his daughter Leah instead of her younger sister Rachel, under the defense, "This is not done in our country-giving the younger before the firstborn" (Gen. 29:26 New Oxford Annotated Bible). The Mahabharata, one of the two major ancient Hindu epics, takes yet a stronger position, putting the marriage of a younger daughter before her elder sister in the same list of sins as arson, breach of contract, and the murder of a teacher, a woman, or a member of a high caste. ${ }^{7}$ In a more recent text, Shakespeare's The Taming of the Shrew, Baptista refuses to allow his daughter Bianca to marry before her elder sister Katherina. Note the role of parents in enforcing the practice. Indeed, demographers have shown that sisters married disproportionately in order of birth in several historical Western contexts; they have interpreted the decline of this practice as evidence of waning parental authority in marriage decisions (Smith 1976; Dillon 2010).

This practice may have evolved as a social norm, or it may simply reflect a family's optimal behavior in the marriage market. First, it addresses issues of fairness and competition within the

\footnotetext{
${ }^{6}$ Importantly, the degree to which the family of origin controls marriage arrangements is continuous, rather than binary. Even in societies that no longer formally adhere to arranged marriage, the family of origin still may influence spouse selection (Goode 1970; Goody 1983; Caldwell et al. 1988).

${ }^{7}$ The father of the sisters is particularly at fault for the out-of-order marriages of his daughters.
} 
family. It equalizes outcomes among daughters by ensuring that parents will find a groom for an unattractive elder daughter even if her younger sister has many suitors, and it minimizes competition between sisters over grooms. Second, the practice can arise in a simple consumption model. If weddings are costly and families face credit constraints, a younger sister's marriage prevents her elder sister from marrying for quite some time. As a result, liquidity-constrained parents who wish to marry all daughters in their youth feel compelled to marry their daughters in strict order of birth. Third, the practice is optimal when search for grooms takes time. Because the probability of finding a willing mate declines rapidly after youth, an unmarried younger daughter's option value to her parents is greater than her older sister's. Parents thus marry their older daughter first.

The importance of marriage by order of birth in South Asia is apparent in DHS data from Bangladesh, India, Nepal, and Pakistan, which Section 4 introduces in greater detail. Specific data on sisters' marriage ages are not available, but because South Asian newlyweds move in with the groom's parents, one can gauge the importance of marriage by sex-specific birth order by examining what fraction of girls leave home before their older sisters. If parents are constrained to marry their daughters in order of birth, then the fraction of girls who leave home out of order will be lower than the fraction predicted based on their ages alone. To implement this test, I restrict the sample to families with exactly two daughters, estimate a regression of parental coresidence on age indicators, and then predict the probability that each daughter lives at home. Among families with two daughters aged 15-24, the predicted probability that the younger daughter has left home but her older sister remains is 12 percent, but the actual probability is 3 percent. If one repeats this exercise for families with three daughters, the predicted probability that a daughter has left home while her older sister remains is 27 percent, compared to an actual probability of 7 percent.

Figure 1, which uses the same data to plot rates of parental coresidence by age and sexspecific birth order, gives further evidence that sex-specific birth order matters for marriage. The figure presents graphs for families with two, three, and four girls. Each graph shows clear evidence that sex-specific birth order influences age at marriage. At each age, the oldest sister is most likely to have left home, followed by the next-oldest, the third-oldest, and then the youngest. The differences between older and younger sisters are substantial; among families with two daughters, the median younger daughter leaves home roughly two years older than the median older daughter. A regression of a parental coresidence indicator on the number of older brothers, the number of older 
sisters, age effects, and maternal fixed effects confirms that these patterns reflect sex-specific birth order, rather than birth order generally. The coefficient on the number of older sisters is 0.060 [S.E. $=0.010$ ], whereas the coefficient on the number of older brothers is 0.007 [S.E. $=0.011$ ]

\section{Sister Effects in a Model of Search for Grooms}

This section develops a simple search framework for understanding how the practice of marrying daughters in order of birth, which features prominently in most systems of arranged marriage, affects marriage timing and spousal choice. The framework rests on three basic assumptions: parents wish to marry their daughters in their youth, parents care about the quality of their daughters' husbands, and potential husbands of variable quality arrive at the household at a slow rate. As shown below, these three assumptions provide one rationalization for marriage by birth order, although the empirical work does not address the origins of the practice. The framework's main takeaway points would hold even if the practice arose partly for other reasons.

In the framework, a family has either one or two daughters. Daughters vary only in age $a_{i}$, with $i=o$ for an only daughter and $i=y, e$ for the younger and elder daughters in a two-daughter family. Let $\Delta \equiv a_{e}-a_{y}$ be the age gap between the elder and younger daughters. Daughters are marriageable only until age $\bar{a}$, after which they transition to spinsterhood. ${ }^{8}$ In each period, a groom arrives with probability $\lambda \in(0,1)$. Each groom is characterized by quality $q$, drawn from a distribution $F$ with full support on $[Q, \bar{Q}], Q \leq 0<\bar{Q}$. If a groom arrives, the parents decide whether to accept him, and if so, which daughter to marry (irreversibly). If the parents reject, the process repeats in the next period. In each period, parents obtain payoff $q$ if a daughter is married to a husband of quality $q$ and zero if she remains unmarried. This setup is highly stylized-for instance, it assumes that groom quality is equally valuable for all daughters and that the arrival rate of grooms is invariant to the number of daughters-but perturbations to these assumptions to not alter the framework's first-order implications. ${ }^{9}$

As is standard in optimal stopping problems, the parents accept a groom if and only if his

\footnotetext{
${ }^{8}$ In much of South Asia, once a woman reaches her later twenties, a suitable spouse is extremely hard to find.

${ }^{9}$ In a model with a variable arrival rate of grooms, one can obtain the main results by assuming that the arrival rate increases less than one-for-one with the number of daughters in the household. That assumption is reasonable in many parts of rural South Asia, where the groom's search party arrives at a village and then visits households within the village that have potential brides. Additionally, parents typically only offer their oldest daughter (as is implied by the model), so in equilibrium, each groom has access to only one daughter per household.
} 
quality exceeds a reservation level. Because the problem is non-stationary, reservation quality varies with age. The Theory Appendix derives the optimal policy for the one-daughter family by backwards induction, yielding a recursive solution:

$$
\begin{gathered}
q_{o}(a)-q_{o}(a+1)=\lambda \psi\left(q_{o}(a+1)\right) \\
q_{o}(\bar{a})=0
\end{gathered}
$$

where $q_{o}(a)$ is the reservation quality at age $a$ for an only daughter, and $\psi(\cdot)$, defined formally in the appendix, equals the chance that a random groom exceeds the reservation quality times his expected gain over the reservation quality. Therefore, the transition function, $\lambda \psi(\cdot)$, is the product of the probability that an acceptable groom arrives and the expected excess quality of that groom. Since $\lambda \psi(\cdot)>0$, reservation quality decreases with age until $\bar{a}$, when the parents are indifferent between a spouse of quality zero and a never-married daughter. Additionally, if quality is log-concavely distributed, then $\psi^{\prime}(q)<0$, so that reservation quality declines more steeply as the daughter approaches spinsterhood. ${ }^{10}$

This solution changes in an intuitive way when the family has two daughters. Note first that the option value of an unmarried younger daughter always exceeds that of an unmarried elder daughter, so the parents will always marry the elder daughter first (as long as she remains of marriageable age). As a result, the practice of marrying daughters in order of birth arises endogenously in the model. After the elder daughter is out of the way, the parents' problem reduces to the only-daughter problem, so that $q_{o}(a)=q_{y}(a)$. In contrast, the elder daughter's marriage problem embeds the cost to her younger sister of waiting another period. The optimal policy is now:

$$
\begin{gathered}
q_{e}(a, \Delta)-q_{e}(a+1, \Delta)=\lambda \psi\left(q_{e}(a+1, \Delta)\right)-\left(q_{y}(a-\Delta)-q_{y}(a-\Delta+1)\right) \\
q_{e}(\bar{a}, \Delta)=0
\end{gathered}
$$

where $q_{e}(a, \Delta)$ is the reservation quality at age $a$ for an elder daughter with an age gap of $\Delta$. The term $q_{y}(a-\Delta)-q_{y}(a-\Delta+1)$ is the cost (in terms of expected spousal quality) of forcing the younger sister to postpone entering the marriage market for another period. This cost is positive, so an elder daughter's reservation groom quality is less than a younger daughter's for all $a<\bar{a}$.

\footnotetext{
${ }^{10} \mathrm{Log}$-concavity is a standard assumption in the economics of search because it rules out pathological cases. A random variable is log-concave if the logarithm of its density function is concave. Examples include the uniform, normal, logistic, and exponential distributions. See Bagnoli and Bergstrom (2005).
} 
Equations (1) and (2) have implications for marriage timing and spousal quality. Because the reservation quality for an older daughter is always less than that of an only daughter, she marries earlier than an only daughter and to a lower quality groom. Meanwhile, a younger daughter has the same age-specific reservation quality as an only daughter, but she enters the marriage market at a later age and thus marries later. Because reservation quality declines with age, her late entry implies lower expected spousal quality. The Theory Appendix confirms this intuition: compared to a girl with no sisters, a girl with a younger sister has higher cumulative marriage risk at any age, a girl with an older sister has lower cumulative marriage risk at any age, and a girl with either an older or younger sister has lower expected spousal quality.

The bulk of the empirical application focuses on the effect of having a younger sister on marriage outcomes. Because the transition function for an elder daughter differs from that of an only daughter solely through the cost of delaying a younger sister, we gain insight into comparative statics on the younger sister effect by examining the properties of this cost. Equations (1) and (2) imply that this cost is $q_{y}(a-\Delta)-q_{y}(a-\Delta+1)=\lambda \psi\left(q_{y}(a-\Delta+1)\right)$. For the purpose of deriving comparative statics, assume that $q$ is log-concavely distributed. Then $\psi^{\prime}(\cdot)<0$, implying that the effect of a younger sister on marriage risk decreases in the age gap $(\Delta)$. Empirically, the absence of exogenous variation in birth spacing makes this comparative static difficult to test. Even so, it may offer useful implications for family planning policies that seek to increase birth spacing. Meanwhile, the arrival rate $(\lambda)$ has an ambiguous influence on the younger sister effect. For a given $q_{y}(\cdot)$, higher $\lambda$ increases the rate of change. But an increase in $\lambda$ also raises $q_{y}(\cdot)$ for all $a<\bar{a}$, which decreases $\psi\left(q_{y}(\cdot)\right)$. The intuition is that, with high $\lambda$, the younger sister's reservation quality declines slowly for most of her lifetime and then drops precipitously in the last few periods before $\bar{a}$; with low $\lambda$, her reservation quality declines more steadily because her parents expect fewer chances to sample from the groom distribution. If the age gap is sufficiently large, the cost of delaying a younger sister decreases in the arrival rate, so that lower arrival rates lead to larger sister effects.

The introduction of love marriage would decouple the sisters' problem, thus eliminating cross-sister effects. Note that the arrival rate and distribution of grooms would change in equilibirum, so the one-sided framework does not allow comparisons of aggregate welfare under arranged marriage and love marriage. In any event, marriage institutions are not binary. The family of origin may have influence over the marriage decision long after the transition to love marriage. 


\section{Data and Methods}

\subsection{Sibling Data from the Demographic and Health Surveys}

To examine how sisters affect one another's marriage and human capital outcomes, I primarily use data from the Demographic and Health Surveys in Bangladesh, India, Nepal, and Pakistan, which share several features in marriage institutions. ${ }^{11}$ Arranged marriage is widespread, non-marriage is a taboo, dowries are commonplace, and post-marital residence is virilocal-the couple resides with the husband's extended family. Appendix Table 1 reports the specific survey years for each country.

I analyze two types of data. The first type derives from the DHS fertility history module, in which women list all of their live births. For each live birth, women report on a series of outcomes, including current parental coresidence. ${ }^{12}$ Because South Asian societies are almost uniformly virilocal, home-leaving is a good proxy for marriage among young women. ${ }^{13}$ However, these data suffer from the important drawback that they do not track a mother's children after they have left the household. For more information on teenagers and adult women, I turn to the DHS sibling history module, which asks respondents to list all children ever born to their biological mothers. Nepal's 2006 DHS is the only survey in South Asia with nationally-representative sibling history data on all women of childbearing age (15-49), rather than ever-married women. The absence of adult sibling data for other South Asian countries is unfortunate, but Nepal's marriage market has a similar structure to those elsewhere in the region, so one might expect to find similar patterns in other countries. I use the Nepal data to analyze the effect of sibling structure on the ages of first marriage and first birth, school enrollment and attainment, literacy, height, weight, and spousal attributes. Because the analysis of spousal attributes necessarily focuses on ever-married women, I minimize selection bias by restricting the sample for this analysis to ever-married women over age 30, who represent over 98 percent of all women over age 30. For statistical power, I supplement these data with the 30-plus sample from the 1996 Nepal DHS, which interviewed ever-married women.

\footnotetext{
${ }^{11}$ The surveys I use represent 13 of the 14 Standard DHS surveys ever conducted in South Asia. The only survey I omit is Sri Lanka's 1987 DHS, a small sample with relatively few variables. Marriage institutions in Sri Lanka differ substantially from those elsewhere in South Asia (Caldwell et al. 1988). Compared to other South Asian societies, the Sinhalese marry much later, have far less parental involvement in spousal choice, and exchange far smaller dowries. The Sinhalese also do not adhere to virilocal post-marital residence.

${ }^{12}$ For girls who have left home, the data do not contain the age at home-leaving.

${ }^{13}$ Among women aged 15-24 in the India 2005-06 DHS, 15 percent of those who lived in a household headed by a parent or a grandparent were married, compared to 90 percent of those with non-parent/grandparent household heads. Other surveys in the region show a similar pattern, which suggests that most young women leave their natal homes to marry rather than to work or study while remaining unmarried.
} 
Although the empirical work relies mainly on South Asian DHS data, supplementary analyses draw on several other data sources, including the 2001 Census of Nepal, the India Human Development Survey, and Demographic and Health Surveys conducted elsewhere in the world.

\subsection{Empirical Strategy}

For both the Fertility Histories and the Sibling Histories, the basic estimation strategy takes advantage of variation in younger siblings' genders. Conditional on a girl having at least $x$ younger siblings, the gender of her $x^{\text {th }}$ younger (ever-born) sibling may be taken as random. A comparison of girls with next-born sisters to those with next-born brothers (or of those with second-subsequent sisters and brothers) therefore allows a causal interpretation. Similarly, conditional on a mother having at least $x$ more pregnancies, the occurrence of a twin birth instead of a singleton birth in the $x^{t h}$-subsequent pregnancy may be taken as random. As a result, a comparison of girls with nextborn twin sisters to those with next-born singleton sisters (or of those with second-subsequent twins and singletons) also allows a causal interpretation. ${ }^{14}$ Because twin births are rare (less than 1 percent of the sample) and thus limit statistical power, most of the analyses focus on the sister-brother comparison rather than the twin-singleton comparison. Additionally, most of the analyses study the outcome of the mother's next pregnancy (conditional on at least one more pregnancy), but some also show results for second-subsequent pregnancy (conditional on at least two more pregnancies).

Although outcome of a given birth is random in ideal circumstances, it may in reality be correlated with pre-birth characteristics. This threat to identification applies mainly to the sisterbrother comparison, due to the prevalence of sex-selective abortion in South Asia (Arnold, Kishor, and Roy 2002; Bhalotra and Cochrane 2010). ${ }^{15}$ Because of the uneven spread of prenatal sex detection technologies, some birth cohorts and countries in this study are subject to concerns about sex-selective abortion, while others are not. ${ }^{16}$ Nevertheless, respondents may be more likely to remember deceased boys than deceased girls, which may also lead to selection bias. Additionally, the Trivers-Willard hypothesis proposes that a woman's status affects the sex of her offspring (Trivers

\footnotetext{
${ }^{14}$ Rosenzweig and Wolpin (1980) were the first researchers to use twins to identify family size effects. More recent examples include Black et al. (2005) and Angrist et al. (2010).

${ }^{15}$ In theory, threats to identification may also apply to the secondary analysis of twin births. However, the data show no evidence that twinning probabilities are correlated with parental characteristics or the composition of older siblings.

${ }^{16}$ Prenatal sex detection technologies became available in India in the mid-1980s and in Bangladesh and Pakistan somewhat later. Their penetration in Nepal remains low.
} 
and Willard 1973). Section 5.1.1 shows that evidence of sex-selection is absent in some estimation samples and quantitatively small in others. Still, I control for the exact permutation of older siblings by sex (e.g., BG, GG, GBG, etc.) as well as the birth interval between the individual and her next-youngest sibling. The likelihood of sex selection declines in the number of older brothers due to a demand for sons, and it increases in the birth interval because longer birth intervals allow for more terminated pregnancies between births (Pörtner 2010). For all of the outcomes of interest, Appendix Table 2 reports unadjusted mean differences between women with younger sisters and brothers. The unadjusted estimates are all similar in magnitude and significance to the regression results below.

For a girl of family $i$ and older sibling composition $j$, I run the following basic regression:

$$
y_{i j}=\delta_{j}+\text { sisters }_{i j}+X_{i j}^{\prime} \gamma+\varepsilon_{i j}
$$

The central variables are $y_{i j}$, a marriage or human capital outcome, and sisters $s_{i j}$, the number of girls born in a subsequent pregnancy (first- or second-subsequent, depending on the analysis). For the sister-brother experiment, sisters $_{i j}$ varies between 0 (for a next brother) and 1 (for a next sister). For the twins experiment, sisters ${ }_{i j}$ varies between 1 (for a singleton sister) and 2 (for twin sisters). The fixed effect $\delta_{j}$ is unique to each permutation of older siblings. The vector $X_{i j}$ contains covariates that vary by sample based on availability. In the analysis of the Fertility Histories, $X_{i j}$ includes the birth interval, maternal and paternal educational attainment, and maternal age, as well as indicators for the girl's age or birth year, the mother's region and sector of residence, household religion, and survey. ${ }^{17}$ In the analysis of the Sibling Histories, it includes the birth interval and indicators for birth year, the decade that the woman's mother initiated childbearing, household religion, and survey. As one would expect in a quasi-experimental setting, the results are not sensitive to the exclusion of these covariates or the $\delta_{j}$ fixed effect. For ease of interpretation, I omit girls who are themselves twins (less than 1 percent of the sample). Although serial correlation across households is likely minimal in this natural experiment, I estimate standard errors conservatively by clustering at the primary sampling unit (PSU) level. I report results from regressions that are weighted using survey weights, but in unweighted regressions produced identical results.

\footnotetext{
${ }^{17}$ The Pakistan DHS surveys do not include a question about religion. Because over 96 percent of Pakistanis are Muslim (Pew Research Center 2009), I code the entire Pakistan sample as Muslim.
} 


\section{Sister Effects on Marriage and Human Capital}

\subsection{Evidence on Home-Leaving}

The analysis first focuses on the process of female home-leaving in the Fertility Histories. The Fertility Histories establish basic patterns across all four countries and allow a detailed examination of how sister effects differ across sub-samples and differ between older and younger sisters.

\subsubsection{Younger Sister Effects on Home-Leaving}

The basic home-leaving result appears in Figure 2, which plots the share of girls living with their parents by age and sex of the next-youngest sibling. Similar patterns emerge in all four countries. Starting in the mid-teenage years, female rates of parental coresidence decline precipitously, as girls leave their natal homes and move in with their husbands' families. Precisely when rates of parental coresidence begin their steep decline (and rates of marriage increase), a persistent gap emerges between girls with younger brothers and sisters. Compared to girls with next-youngest brothers, girls with next-youngest sisters are a few percentage points less likely to be living with their parents.

Table 1 places magnitudes on these graphical differences with ordinary least squares (OLS) estimates of the effect of next-youngest sisters on parental coresidence between ages 15 and 24 . In each panel, the first row reports the coefficient on the younger sister dummy, and the second row reports the control group mean, or the share of girls with younger brothers who still live with their parents. Relative to their counterparts with next-youngest brothers, girls with next-youngest sisters are roughly 3 percentage points more likely to have left home (Panel A). Additionally, girls with second-youngest sisters are roughly 1.5 percentage points more likely to have left home than those with second-youngest brothers (Panel B). Many of the second-youngest sister coefficients are not statistically significant at the individual country level, but a pooled regression with country-byyear fixed effects yields a significant coefficient of -0.015 [S.E. $=0.003$ ]. The weaker effects of secondyoungest sisters are consistent with the search framework's prediction that sister effects decline in the age gap between sisters, but because of compositional differences across samples, the results in Panels A and B are not directly comparable. The point estimates in both panels show some variation across countries, with Bangladesh and Nepal showing lower average rates of parental coresidence and larger effects. However, the basic patterns are similar across all countries. 
The evolution of these effects across ages emerges in Figure 3, which plots younger sister effects from age-specific estimations of equation (3). Panel A graphs the coefficients on the sex of the first-subsequent sibling, and Panel B graphs the coefficients on the sex of the second-subsequent sibling. In Panel A, through roughly age 15, differences between girls with next-youngest sisters and brothers are indistinguishable from zero. During the remainder of the teenage years, the gap widens until it reaches roughly 5 percentage points at age 19. The pattern then reverses course, so that by the late 20s, when almost all women have left home, next-youngest sisters have negligible effects on parental coresidence. The age patterns in Panel B, for second-subsequent siblings, are similar but closer to zero.

Possible threats to causal inference in Tables 1 and 2 include sex-selective abortion, recall error, and the Trivers-Willard hypothesis. To investigate these threats, Appendix Table 3 reports regressions of the next-youngest sibling's gender on the birth interval, the sex composition of older siblings, and several parental characteristics. The results reveal little reason to believe that sex selection will bias the results. Few coefficients are statistically significant, all are small in magnitude, and all vary in sign across countries. The only country with consistent evidence of sex selection is India, where a one-year increase in the birth interval is associated with a 0.3 percentage point reduction in the probability of a female birth, and an increase in the number of older brothers by one is associated with a 0.9 percentage point rise in this probability. But the effects of younger sisters are just as evident outside India as inside it.

The estimates in Tables 1 and 2 may reflect a negative effect of a younger sister on parental coresidence, a positive effect of a younger brother on parental coresidence, or some combination of the two. Table 3 relies on twin births to clarify this ambiguity, focusing on the outcomes of mother's first and second subsequent pregnancies. Panel A repeats the sister-brother comparison for singleton births. Panel B then focuses on pregnancies that only resulted in female births and estimates the effect of twin younger sisters relative to a singleton younger sister. Panel $\mathrm{C}$ does the same for pregnancies that only resulted in male births. In all analyses, girls with mixed-gender twins are excluded from the sample. Under the assumption that twin births are random, the analyses in Panels $B$ and $C$ measure the effect of an additional sibling on home-leaving, rather than the difference between having a sister and having a brother.

In Panel A of Table 3, the usual pattern emerges, with younger sisters causing earlier home- 
leaving relative to younger brothers. The effect is stronger for the first subsequent pregnancy than the second, which is consistent with the idea that younger sister effects diminish in the age gap between sisters. As before, however, the difference in coefficients is confounded by differential selection into the samples with at least one or two subsequent pregnancies.

Panels B and C then give suggestive evidence that the sister-brother difference is due solely to an effect of the number of sisters. Because twin births are rare (200-300 in each regression, or less than 1 percent of the sample), the standard errors are large and the estimates noisy. Even so, in Panel $\mathrm{B}$, the coefficients on the number of girls born in subsequent pregnancies are both negative and, in one out of two cases, statistically significant. The coefficient is larger for the second subsequent pregnancy than for the first, which is surprising, but this is likely the result of sampling error. Certainly, the coefficients are not statistically distinguishable. Meanwhile, Panel C yields coefficients of zero for the number of boys born in subsequent pregnancies. An exogenous increase in the number of younger sisters increases marriage risk, whereas an exogenous increase in the number of younger brothers does not. This result suggests that the sister-brother comparison solely reflects the effect of an additional sister, rather than offsetting (non-zero) effects of sisters and brothers.

\subsubsection{Heterogeneity in Younger Sister Effects on Home Leaving}

A comparison of the next-youngest sister effects across selected subsamples sheds some light on the mechanisms behind the basic result.

\section{A. Younger Sister Effects by Demographic Group Table 2 pools data from all four countries and} then divides the sample by several relevant characteristics. ${ }^{18}$ As a basis for comparison, column (1) reports the baseline estimate of the younger sister effect in the pooled data. Because India's sample is so large relative to other countries', the baseline estimate in the pooled data, -0.028 , is very close to the estimate for India in Table 1, Panel A. ${ }^{19}$

\footnotetext{
${ }^{18}$ The search model has no specific predictions for how sister effects vary with religion, so Table 2 does not report effects by religion. For completeness, I analyzed Hindus and Muslims separately and found no significant difference between the two in the pooled sample. The effects are larger for Hindus than for Muslims in Bangladesh, India, and Nepal, but Pakistan (which is predominantly Muslim) exhibits large effects.

${ }^{19}$ One could argue that the coefficient on the gender of the next-youngest ever-born sibling is not the estimand of interest. If the effects operate through a marriage search channel, then one should take interest in the effect of a younger sister who is still alive when her older sister reaches marriageable age. In a two-stage least squares (2SLS) regression that uses the gender of the next-youngest ever-born sibling as an instrument for a surviving next-youngest sister at age fifteen, the effect estimate is 14 percent larger than OLS estimate. This estimator assumes that the effect of the younger sibling's gender operates only through circumstances in young adulthood. While this exclusion restriction may not hold
} 
Columns (2) and (3) of Table 2 show that the effects are stronger for girls who grew up in rural areas than for their urban counterparts. This result suggests that a low arrival rate of grooms intensifies the observed effects because parents fear they will fail to find a spouse for their younger daughter. Urban areas are likely characterized by higher arrival rates than rural areas. In urban areas, marriage markets are thick, matchmakers and newspaper classifieds are easily accessible, and the search process does not involve (sometimes arduous) travel to neighboring villages. The theoretical framework reveals that cross-sister effects on marriage risk vary ambiguously with the arrival rate, so one can interpret the urban/rural difference as preliminary evidence on the sign of this comparative static. Section 5.1.3 estimates the arrival rate comparative static more formally.

The remainder of Table 2 examines heterogeneity by parental socioeconomic status and the age gap between sisters. Columns (4) and (5) show that the effects are stronger among girls whose fathers have above-median educational attainment, implying that the effects are not driven by economic constraints affecting only poor families. Finally, columns (6)-(8) subdivide the sample based on the next birth interval. The model predicts stronger effects of younger sisters when the age gap is small. Indeed, the effect estimates decrease with the age gap, but the differences in coefficients are statistically insignificant. Importantly, birth spacing is associated with parental socioeconomic status, so the comparison across subsamples does not isolate the comparative static of interest.

B. Younger Sister Effects and the Arrival Rate of Grooms Intuition suggests that the a younger sister's effect on marriage risk may be especially strong when grooms arrive at a slow rate because parents fear that they will fail to find their younger daughter a groom while she is still desirable on the marriage market. The model clarifies that this comparative static is in fact ambiguous, because the slow arrival rate also decreases the rate at which the younger daughter loses value in her final years of her marriageable age span. How cross-sister effects vary with the arrival rate is an empirical question.

The true arrival rate is unobservable, but one can use marriage market demographics as proxies. The starting point is a meeting function, $m(M, F)$, which gives the number of meetings per unit of time as a function of the number of marriageable men $(M)$ and women $(F) .{ }^{20}$ The literature exactly, the estimate is nonetheless informative.

${ }^{20}$ I refer to $m(\cdot)$ as a "meeting function" rather than a "matching function" to emphasize that a meeting does not necessarily translate to a match. 
commonly specifies this function as a Cobb-Douglas technology, so that $m(M, F)=M^{\alpha} F^{\beta}$. Then from a female perspective, the arrival rate of grooms is:

$$
\lambda(M, F)=\frac{m(M, F)}{F}=\left(\frac{M}{F}\right)^{\alpha} F^{\alpha+\beta-1}
$$

Equation (5) expresses the arrival rate of grooms as a function of observable features of the marriage market: namely, the sex ratio and the number of women. Research on search in both the labor and marriage markets points to two empirical regularities. ${ }^{21}$ First, the arrival rate increases in the tightness of the market (here measured by the sex ratio), so that $\alpha>0$. Second, the meeting (or matching) function is typically characterized by constant returns to scale, so that $\alpha+\beta=1$. This implies that doubling the size of the market leads to a doubling of the number of meetings.

To use equation (5) in a linear regression, take logs to obtain:

$$
\ln \lambda=\alpha \ln \left(\frac{M}{F}\right)+(\alpha+\beta-1) \ln F
$$

One can implement this specification of the log arrival rate using basic data on the demographics of the marriage market. Not all DHS samples can be linked to data on local marriage markets, but the 2001 and 2006 Nepal DHS samples are geocoded, allowing a merge to district-level information from the 2001 Census of Nepal (Nepal Central Bureau of Statistics 2010). Using this linked Nepal dataset, I interact the next-youngest sister dummy with the logarithms of the marriage market sex ratio and the number of women in the marriage market. Most marriages in Nepal take place within district and within caste or ethnicity, so I aggregate marriage markets at the district-by-ethnicity level. ${ }^{22}$ Men marry at ages 20-24, and women marry at ages 15-19. For each of three 5-year female marriage cohorts that were aged 15-19 in 1996, 2001, and 2006, I use the 11\% census micro-sample to estimate the number of women in the cohort, as well as the ratio of men in the next-oldest five-year cohort to women in the cohort. ${ }^{23}$ To avoid bias from a badly measured sex ratio denominator, I omit

\footnotetext{
${ }^{21}$ On labor markets, see the review by Petrongolo and Pissarides (2001). On marriage markets, see Angrist (2002), Botticini and Siow (2009), and Abramitzky et al. (2010).

${ }^{22}$ I assume that cross-district marriage-related migration is minimal, although I do not have specific data on this issue. Marriage-related migration would tend to bias the coefficients towards zero.

${ }^{23}$ Respondents reported their district of residence 5 years before, so for the 1996 cohort, I use the ratio of men age 20-24 to women 15-19 five years before the census. For the 2001 cohort, I use the current ratio men age 20-24 to women age 15-19. For the 2006 cohort, I use the current ratio of men age 15-19 to girls age 10-14 in the current district of residence. The 1996 and 2006 sex ratio estimates will be accurate if mortality and international emigration are minimal.
} 
district/ethnicity-level cohorts with fewer than fifteen women in the micro-sample. ${ }^{24}$ The resulting marriage market sex ratio has a mean of 0.8 and a standard deviation of 0.26 . The mean sex ratio is below 1 because population growth implies that the number of 15-19 year-olds exceeds the number of 20-24 year-olds.

Table 4 adds these measures and their interactions with the next-youngest sister dummy to specification (3). The new specification also includes fixed effects at the 5-year marriage cohort, district, and caste-ethnicity level. To ease interpretation, I run one regression as specified above, with both marriage market variables in logs, and one regression that uses the level of the sex ratio rather than its logarithm. The dependent variable is an indicator for parental coresidence.

Younger sister effects on home-leaving are stronger when grooms are scarce but do not depend on the scale of the marriage market. The levels and logs specifications of the sex ratio lead to similar estimates, which is unsurprising because sex ratios are on average close to 1 , so that $\ln \left(\frac{M}{F}\right) \approx \frac{M}{F}-1$. The coefficient of 0.138 in column (1) implies that a move from the 75 th percentile (0.96) to the 25 th percentile (0.64) of sex ratio distribution increases the younger sister effect on home-leaving by 4 percentage points. Note also that the probability of parental coresidence tends to decrease in the relative supply of grooms (i.e., the main effect of the sex ratio), implying that the risk of non-marriage is high when grooms are scarce. Interestingly, both specifications indicate little role for the absolute number of women of the marriage market, which is suggestive evidence of constant returns to scale in the meeting function.

The preceding analysis is based on cross-sectional variation in marriage market demographics, which poses some concerns about identification. Variation in marriage market sex ratios results from variation in population growth, (pre- and post-natal) sex selection, and migration. Unfortunately, no credible instrument exists for marriage market sex ratios in Nepal. Nonetheless, the strength of the association between younger sister effects and the relative supply of grooms reinforces a marriage market interpretation of the main results.

C. Younger Sister Effects and the Prevalence of Arranged Marriage Although sisters may constrain one another's marriage timing even in the absence of formal arranged marriage, the constraints are likely to be especially important when parents have a strong say in their daughters'

\footnotetext{
${ }^{24}$ The results are not sensitive to modifications of the fifteen woman cutoff.
} 
marriages. The DHS contains no information on parental involvement in marriage arrangements, but another survey, the India Human Development Survey (IHDS), does. A nationally representative household survey, the IHDS includes a fertility history module similar to that found in the DHS, a marriage history module asking adult women to report how their marriages were arranged, and a marriage practices module asking women to describe some aspects of marriage practice in their communities. I use the IHDS data to measure whether the next-youngest sister effect varies with the prevalence of arranged marriage.

Because the data on marriage arrangements are self-reported but the data on home-leaving and sibling composition are mother-reported, I cannot estimate individual heterogeneity in sister effects by type of marriage arrangement. ${ }^{25}$ However, I can aggregate self-reported marriage arrangements of young women at the district level and ask whether sister effects vary with the district-level prevalence of arranged marriage. ${ }^{26}$ To measure the district-level prevalence of arranged marriage, I calculate the shares of young women age 25-29 who arranged their own marriages, arranged their marriages jointly with their parents, and had no input into their marriage arrangements. I then interact the next-youngest sister dummy in specification (3) with the share self-arranged and the share with no say. Looking across districts, the share self-arranged has a mean of 0.06 and first, second, and third quartiles of $0.00,0.00$, and 0.07 , respectively. The share with no say has a mean of 0.36 and first, second, and third quartiles of $0.00,0.30$, and 0.60 , respectively.

The results of this exercise, presented in Table 5, show that younger sister effects on home leaving are significantly weaker in districts with a greater share of self-arranged marriages. ${ }^{27}$ At the same time, relative to joint marriage arrangements, parent-only marriage arrangements do not significantly change the magnitude of the younger sister effects. In the full specification in column (4), the coefficient on the interaction of the next-youngest sister dummy with the share self-arranged 0.19 [S.E. $=0.09]$. A move from the median to the 75th percentile of the share self-arranged shrinks the younger sister effect by 1.3 percentage points, and a move from the 75 th percentile to the 90 th percentile shrinks it by a further 2.3 percentage points.

\footnotetext{
${ }^{25}$ Individual-level variation in the type of marriage arrangement may also be endogenous to sibling composition.

${ }^{26}$ Unlike the $11 \%$ census sample from Nepal, the IHDS sample is too small to disaggregate districts by caste.

${ }^{27}$ The uninteracted coefficient in column (1) of Table 6 may appear large relative to the DHS results for India. However, when the regressions are estimated with sampling weights, the coefficients are much closer. In the India DHS data, the weighted regression coefficient is 0.034 . In the India Human Development Survey data, the weighed regression coefficient is 0.039 . The IHDS survey weights are not representative at the district level, so the weights are not helpful for the analysis in Table 6.
} 
These results strongly imply that sister effects intensify with more family involvement in marriage arrangements. But we should note that the prevalence of arranged marriage is likely correlated with social conservatism more generally. If conservatism is associated with strong social norms for marriage by birth order, then arranged marriage may not be the culprit per se. In either case, however, adherence to orthodox marriage practices is key to putting sisters' interests at odds with each other.

\subsubsection{Older Sister Effects on Home-Leaving}

The search framework has the important prediction that the effects of older and younger sisters have opposite sign. Parents hasten to marry an older daughter but delay in marrying her younger sister. However, mean differences between girls with older brothers and girls with older sisters may reflect selective fertility, rather than the effects of older siblings. Because of the demand for sons, parents are far more likely to continue having children after a female birth than after a male birth (Filmer et al. 2010). For young women with at least one older sibling in the pooled sample, Appendix Table 4 regresses the gender of the next-oldest sibling on family characteristics. Girls with next-oldest sisters have fewer older brothers (not counting the next-oldest birth), shorter birth intervals, more educated and older mothers, and later birth years than girls with next-oldest brothers. This implies that a mean comparison between girls with next-oldest brothers and sisters may yield a biased estimate of the effect of an older sister.

The selection problem is most intuitive if we view the older sibling as the unit of observation. As before, consider a child from family $i$ with older sibling composition $j$. Let female $i j$, $S_{i j}$, and $Y_{i j}$ be indicators for the child's gender, the presence of a next-youngest sister, and the presence of a next-youngest sister who lives with her parents, respectively. In more general language, female ${ }_{i j}$ is the treatment indicator, $S_{i j}$ is the sample selection indicator, and $Y_{i j}$ is the outcome. Then:

$$
\begin{gathered}
S_{i j}=S_{i j}^{1}\left(\text { female }_{i j}\right)+S_{i j}^{0}\left(1-\text { female }_{i j}\right) \\
Y_{i j}=S_{i j} \cdot\left\{Y_{i j}^{1}\left(\text { female }_{i j}\right)+Y_{i j}^{0}\left(1-\text { female }_{i j}\right)\right\}
\end{gathered}
$$

where $\left(S_{i j}^{1}, S_{i j}^{0}\right)$ are potential sample selection probabilities and $\left(Y_{i j}^{1}, Y_{i j}^{0}\right)$ are potential outcomes. We observe only $\left(\right.$ female $\left._{i j}, S_{i j}, Y_{i j}\right)$ but wish to make inferences about moments of $Y_{i j}^{1}-Y_{i j}^{0}$ : the effect of a child's sex on a younger sister's propensity to live with her parents, were a younger sister to exist. 
The econometrics literature suggests a few ways to estimate treatment effects under endogenous sample selection. Horowitz and Manski (2000) propose making worst-case assumptions about the missing outcomes to generate treatment effect bounds that require no assumptions about the selection process. But if both the treatment and control groups select out of the sample at reasonably high rates, as is the case here, Horowitz-Manski bounds become uninformative. ${ }^{28}$ However, Heckman $(1974,1979)$ and Lee (2009) show that added structure on the selection process can improve identification. Both approaches depend heavily on a latent variable threshold-crossing model of sample selection, which is equivalent to the monotonicity condition that $S_{i j}^{1}-S_{i j}^{0}$ has weakly the same sign for all children (Vytlacil 2002). Heckman's parametric selection correction model yields a point estimate of the treatment effect but is only robust when an instrument for selection-a variable that affects selection but bears no direct effect on the outcome-exists. In contrast, the procedure of Lee provides non-parametric bounds on the treatment effect without requiring such an exclusion restriction. This procedure involves identifying the excess number of observations in the group with a higher selection rate and then trimming the left and right tails of that group's outcome distribution by this excess number of observations.

I use the methods of both Heckman (1974) and Lee (2009) to assess the extent of selection bias in OLS estimates of the older sister effect on parental coresidence. ${ }^{29}$ As a first step to implementing these methods, one must justify the monotonicity assumption. In South Asia, where parents have a demand for sons, the monotonicity condition generally implies that all couples who stopped childbearing after a girl would have also stopped after a boy. This condition may not hold exactly for all families, but because son-biased fertility stopping behavior is so pervasive in South Asia (Filmer et al. 2010), it is a reasonable approximation. ${ }^{30}$ Nonetheless, if parents also have a demand for gender diversity, a female birth may decrease fertility in families with many boys but without many girls. To account for this possibility, I allow the effect of a girl on fertility continuation to differ by the exact composition of older siblings in both the selection correction and bounds estimations.

\footnotetext{
${ }^{28}$ Because we only observe outcomes for girls, who represent roughly half of next-born children, the attrition rate would be approximately one-half even in the absence of fertility cessation.

${ }^{29}$ In implementing both estimation procedures, I account for clustering in the DHS survey design. The maximum likelihood version of Heckman's selection correction model is easier to adjust for clustering than the two-step version, so I use the former. For consistency with the other results in the paper, I use a linear probability model for the second-stage equation. For the bounds estimator, Lee provides formulas for asymptotic standard errors only in the i.i.d. case, so I block-bootstrap the bounds estimator at the PSU-level.

${ }^{30}$ Son-biased fertility stopping behavior reflects the tendency to desire more sons than daughters. For example, in India's 2005-06 DHS, 22 percent of women desire more sons than daughters, 76 percent of women desire the same number, and less than 3 percent desire more daughters than sons.
} 
In the selection correction model estimations, I interact the gender dummy with indicators for the exact composition of older siblings. In the bounds estimations, I compute separate bounds for each composition of older siblings and then average across them, weighting by sample size.

The monotonicity condition requires a careful choice of the analysis sample. One sample of interest is every individual in the fertility histories over age 15, which includes every older sibling of the 15-24 age group. But the inclusion of individuals aged 26 and above may violate the monotonicity condition, since an initial spike in parental fertility following a female birth may then decrease the probability that a younger sibling lands in the 15-24 age group. As a result, I analyze how the genders of individuals aged 16-25 affect rates of parental coresidence among their younger sisters aged 15-24. This approach exacerbates sample selectivity because it leaves a short period for the birth of a younger sibling, but it makes the monotonicity condition plausible.

A second step to implementing the Heckman selection correction model is the choice of an instrument for sample selection. Based on the logic that women become less likely to continue childbearing as they age, I use the mother's age at the older sibling's birth as an instrument for whether a younger sibling is born. Because the mother's age at a given child's birth is correlated with her age at first birth, I control for her age at first birth in both the selection equation and the outcome equation. ${ }^{31}$ I also report a specification that controls for the mother's age at first birth, age at first marriage, and educational attainment, as well as the father's educational attainment. In both specifications, the exclusion restriction—-that absent selection, children born longer after their mothers' first births would have similar home-leaving propensities to those born sooner after their mothers' first births-is strong, but the results are nonetheless instructive. The DHS does not offer an obviously superior instrument for selection.

Table 6 exhibits the uncorrected OLS estimates, the Heckman selection-corrected estimates, and the Lee bounds. To clarify the selection process, Table 6 presents separate estimations for birth orders 1-5. For comparison, column (1) presents estimates the effect of next-youngest sibling gender. Column (2)-(7) contain estimates of the effect of next-oldest sibling gender. These effects do not apply to first-born children (who have no older siblings), and the Heckman models are not estimable for second-born children (for whom the mother's age at first birth is the same as the mother's age at the next-oldest sibling's birth).

\footnotetext{
${ }^{31}$ The results are also robust to omitting the mother's age at first birth.
} 
The results support the queuing theory's prediction that younger and older sisters have opposite effects. Column (1) shows that the presence of a younger sister has a robust negative effect on parental coresidence across all birth orders. In contrast, the results in columns (2)-(7) strongly suggest that the presence of an older sister has a positive effect on parental coresidence. The uncorrected OLS results in column (2), which use the full sample of women aged 15-24 who have at least one older sibling, indicate that younger women with older sisters exhibit significantly higher rates of parental coresidence than their counterparts with older brothers. Selection bias is possible, however, so columns (3)-(7) perform the selection-correction and bounding procedures. The selectioncorrected estimates (columns [3]-[4]) are broadly similar to the uncorrected OLS estimates in both magnitude and statistical significance. The nonparametric bounds are necessarily less precise, but they too support the hypothesis that younger and older sisters have opposite effects. Column (5) shows the average proportion of observations trimmed from each older sibling composition stratum, and columns (6) and (7) display the trimmed bounds. Except among 5th-born women, for whom the trimming proportion is fully 11 percent, both the lower and upper bounds on the older sister effect are positive. Unfortunately, the lower bound is too close to zero to statistically reject a zero effect. Coupled with the OLS and Heckman results, however, the results are strongly consistent with positive older sister effects on parental coresidence-compelling evidence that girls queue to leave the household.

\subsection{Evidence on Marriage Age, Human Capital, and Spousal Quality}

The Fertility History results establish some compelling facts about how sisters affect each other's home-leaving. But because the Fertility Histories fail to track these women after they leave home, they cannot provide answers to several key questions. Do the effects of younger sisters on homeleaving indeed correspond to effects on marriage? If so, does the earlier marriage of women with younger sisters come at the expense of their education? And what are the implications for spousal

quality? This section explores these questions using women's Sibling Histories from Nepal. The Sibling History data do not provide enough information to compute selection-corrected estimates of the effects of older sisters, so the section focuses only on the effects of younger sisters. 


\subsubsection{Younger Sister Effects on Marriage Age and Human Capital among Teenagers}

Figure 4 plots rates of parental coresidence, never-marriage, and school attendance by age and younger sibling gender. The top panel shows rates of parental coresidence in a graph analogous to Figure 2, this time focusing only on the 2006 Nepal Fertility History data. The middle panel displays rates of never-marriage among young women in the same survey's Sibling History data. The bottom panel combines Fertility History data on coresident daughters with self-reported data on women fifteen and older. By combining the samples in this way, one can observe precisely when schooling gaps emerge between girls with younger brothers and sisters. ${ }^{32}$

The patterns in Figure 4 match a theory in which same-sex sibling competition emerges only when girls are at risk of marriage. From age three to age fifteen, girls with younger brothers and sisters have identical school attendance rates. This pattern holds both for ten-year-olds, who have high school attendance rates, and for three- to five-year-olds, who do not. At age sixteen, a large gap in school attendance emerges between girls with younger brothers and sisters, only to close at age 19, when school attendance rates become quite low. These are precisely the ages at which girls are most likely to marry.

Based on these patterns, Table 7 estimates younger sister effects on marriage, childbearing, school enrollment, and literacy among women aged 15-19. A younger sister increases a teenage girl's probability of marriage by $5 \frac{1}{2} 2$ percentage points and decreases her probability of attending school in the previous year by $6 \frac{1}{2}$ percentage points. Girls often leave school in advance of their weddings, so the larger effect on school attendance does not necessarily imply that non-marital forces are at work. (In any event, the effects are not statistically distinguishable.) The effects on literacy and fertility are small and insignificant, which may be due to the low rates of illiteracy and maternity in this young sample.

\subsubsection{Younger Sister Effects on Marriage Age and Human Capital among Adults}

Similar effects on marriage risk and human capital are also evident among women later in the lifecycle. Panel A of Table 8 presents analyses based on all women aged 15-49. The first two columns

\footnotetext{
${ }^{32}$ Changes in sample composition pose a potential problem for this approach. Girls in the Fertility Histories all have mothers younger than 50, whereas those in the Sibling Histories have mothers of any age. However, adjustment for the year of the mother's first birth does not change the patterns in Figure 2. (The year of the mother's first birth serves as a proxy for her age; her actual age is not available in the Sibling Histories.)
} 
report Cox hazard regressions based on equation (3). ${ }^{33}$ The presence of a younger sister raises a woman's risk of marriage and childbearing by slightly over 10 percent. In the time metric, this represents an average effect of approximately half a year. Younger sisters cause earlier marriage, which also appears to hasten childbearing.

The remaining columns in Panel A of Table 8 examine the effects of younger sisters on other female outcomes in adulthood. Column (3) shows a moderate (but only marginally significant) negative effect on the highest grade completed, while column (4) indicates a large, statistically significant, positive effect on illiteracy. Of women with younger brothers, 44 percent are illiterate, compared to 47 percent of women with younger sisters. This finding is consistent with the results of Field and Ambrus (2008), who find that early marriage reduces female literacy in Bangladesh. Women with younger sisters also display slightly lower body mass indices (BMIs) than women with younger brothers $(p<0.08) .{ }^{34}$ However, younger sisters have no effect on height, an indicator of early-childhood conditions. This result supports the hypothesis that the effects of younger sisters emerge only in young adulthood.

\subsubsection{Younger Sister Effects on Spousal Attributes}

Shorter search time implies lower spousal quality. For obvious reasons, data on spousal quality are available only for ever-married women. I thus restrict attention to women over age 30, whose rates of never-marriage are extremely low (less than 2 percent). ${ }^{35}$ Because this reduces the sample size substantially, I supplement the 2006 sample with data from the 1996 Nepal DHS. The 1996 survey also included a sibling history module, but it only interviewed ever-married women, making it inappropriate for some of the preceding analyses. Nonetheless, the sample design introduces no new biases for the study of spousal quality.

Panel B of Table 8 analyzes this sample of women aged 30-49. For completeness, the table first verifies that younger sisters increase the hazards of marriage and childbirth in this sample of older women. The effects remain positive and statistically significant, although they are smaller than in the 2006 full-sample results. ${ }^{36}$ The human capital effects are similar to before, and the coefficient for

\footnotetext{
${ }^{33}$ To avoid possibly inappropriate proportionality restrictions, the Cox models stratify by the composition of older siblings, instead of including fixed effects. Otherwise, the specification is identical to equation (3).

${ }^{34}$ The standard deviations of BMI and height are 3 and 6, respectively.

${ }^{35}$ Nearly all ever-married women in the sample reported their husbands' characteristics.

${ }^{36}$ Appendix Figure 1 shows that secular change across cohorts may account for the different results in the main sample
} 
educational attainment is now significant at the 5 percent level.

Columns (11)-(14) then show that younger sisters also reduce spousal quality and household wealth in adulthood. The husbands of women with younger sisters have completed 0.2 fewer grades and are 4 percentage points less likely to have skilled occupations than their counterparts whose wives have younger brothers. Durable goods ownership, measured in an index normed to have mean 0 and standard deviation 1, is also slightly lower in the households of women with younger sisters. However, although the effects on spousal education and occupation are statistically significant at the 5 percent level, the effect on household wealth is only statistically significant at the 10 percent level. Finally, younger sisters do not affect the age of their older sisters' husbands, a result consistent with the small, insignificant estimates of the value of a groom's age that arise in hedonic dowry regressions (e.g., Rao 1993). These results suggest that the constraints younger sisters place on their older sisters' marriage arrangements lead to reductions in spousal quality.

\section{Alternative Explanations for Sister Effects}

The results in Section 5 are strongly consistent with a marriage search framework, but several alternative theories also predict that women's outcomes vary with the sex composition of their siblings. The leading alternatives focus on marriage costs, the demand for male and female labor, son-biased resource allocation, and son-biased fertility stopping behavior. Sections 6.1-6.3 discuss the alternative mechanisms and explore whether their implications match the data. ${ }^{37}$ The basic conclusion is that no single alternative theory can account for all the patterns observed in the data.

\subsection{Dowry and Liquidity Constraints}

The first alternative explanation for the patterns in Section 5 remains firmly rooted in the marriage market but concentrates on the family consumption problem rather than search. To marry their daughters, South Asian families pay dowries that regularly reach several times their annual income

and the over-30 sample. For four decadal birth cohorts, the figure plots the share of women married by ages 14, 15, 16, 17, and 18. Younger sisters increase marriage risk only among cohorts born after 1970. This coincides with population growth, which raised marriage market sex ratios, and also with the rapid growth of the Nepali public school system, which increased the dispersion of groom quality and the value of parental coresidence for teenage daughters.

${ }^{37}$ Sections 6.1-6.3 discuss mainly economic mechanisms, rather than gender-specific personality effects, which arise in the literature on industrialized countries (Butcher and Case 1994). The link between such personality effects and marriage risk is unclear. Additionally, personality theories give little reason to expect the effects to vary with the prevalence of arranged marriage and the demographics of the marriage market. 
(Anderson 2007a). A liquidity-constrained family must delay its younger daughter's marriage to allow time to accumulate a second dowry. Because dowries increase with bridal age (Field and Ambrus 2008), the delay increases her dowry, which the family may offset by marrying her older sister at a younger age. Like the search framework, this simple theory predicts opposite effects of older and younger sisters on marriage age.

The sub-sample analyses in Table 2 already provide suggestive evidence against the dowry theory. Girls whose fathers have above-median educational attainment display stronger effects than girls whose fathers are less educated. If dowries and liquidity constraints were important, then the effects would presumably be stronger in poorer households (with less educated fathers), where borrowing constraints are more likely to bind. Without more information on the size of the dowry and the nature of borrowing constraints, this pattern remains suggestive. Nonetheless, the stronger effects in better-off households are difficult to reconcile with a model of liquidity constraints.

The data offer two testing grounds for the dowry theory. The first is Nepal, which exhibits significant regional variation in marriage institutions. In the terai lowlands, where nearly half of Nepal's population lives, dowry is a deep-seated institution (Niraula and Morgan 1996; Sah 2008). Dowries are large and widespread in terai marriages, and parents take on overwhelming debt to marry their daughters. In contrast, dowries are smaller and less common in Nepal's other two ecological regions, the hills and mountains. If the interaction of dowry and liquidity constraints drives the home-leaving patterns, then these patterns should be stronger in the terai than in the hills and mountains. As column (1) of Table 9 reveals, the opposite is true. In the hills and mountains, younger sisters decrease parental coresidence in early adulthood by over 8 percentage points. This compares with an effect of less than 2 percentage points in the terai. ${ }^{38}$ This stark regional difference suggests that dowry cannot play a primary role in explaining the main results of the paper. ${ }^{39}$

The second testing ground is India, where the IHDS data allow for more precise measurement of dowry. The IHDS features a module on marriage practices, including a series of questions on the types of "gifts" typically transferred during a daughter's wedding, from precious metals, to

\footnotetext{
${ }^{38}$ The younger sister effect is also smaller in the terai than in the hills and mountains if one omits Tharu women from the sample. The Tharu, an ethnic group from the western terai, do not exchange dowries (Gurung and Kittelsen 1996).

${ }^{39}$ The size and direction of the regional difference was unexpected, but one can easily reconcile it with the search framework. Because of the rugged terrain in the hills and mountains, communities are more isolated than in the terai. Travel to neighboring communities is more cumbersome, which may intensify search frictions. Additionally, young men migrate from the hills and mountains to the terai for work; as a result, the terai has marriage market sex ratios that are approximately 10 percentage points higher than the hills and mountains.
} 
livestock, to cash. I use the responses of the young woman's mother, although the results are similar if one instead uses a district-level average that leaves out the young woman's mother due to endogeneity concerns. To aggregate the various gifts, I take the first principal component of the vector of the mother's responses. I then interact this measure of dowry with the next-youngest sister dummy. The results, in column (2) of Table 9, show no evidence that sister effects are more pronounced in communities with larger dowries. ${ }^{40}$

\subsection{Household Labor Demand}

Apart from the marriage market explanations, sibling sex composition may affect marriage age because of complementarities in household production. If opposite-sex siblings are complements in household production, but same-sex siblings are substitutes, then a sister's presence in the household decreases the demand for female labor, whereas a brother's presence increases it. However, while this theory predicts higher home-leaving (and marriage) among young women with sisters, it gives no reason for the opposite effects of older and younger sisters that are suggested by the data. Furthermore, Table 3 shows that the birth of twin brothers relative to a singleton brother does not affect female home-leaving. Finally, the school attendance differences in Figure 4 are also inconsistent with the labor demand theory. Girls with brothers are more likely to attend school than girls with sisters; the labor demand theory predicts that they should be working rather than studying. ${ }^{41}$ Household demand for male and female labor is unlikely to account for the patterns in Section 5.

\subsection{Son Bias}

The existing literature on the effects of sibling sex composition in resource-poor settings has emphasized yet another mechanism: a bias for sons in both intrahousehold resource allocation and fertility stopping. ${ }^{42}$ Families may substitute resources from girls to boys, so that a girl benefits from the birth of a sister rather than a brother. However, brothers raise per capita resources in the household, both

\footnotetext{
${ }^{40}$ The size of the dowry may be correlated with household income, which in turn may be inversely related to the incidence of liquidity constraints. In unreported results, I control for the education of the young woman's father and for the interaction of his education with dowry size. The results still fail to support the dowry theory.

${ }^{41}$ Using data from Nepal, Edmonds (2006) finds that both boys' and girls' labor supply decreases if the next-youngest sibling is female, with the effect substantially larger among boys. However, this effect is concentrated only among closely spaced children, whereas the effects on marriage risk are evident at wider birth spacing as well. Furthermore, in unreported estimates, teenage boys with younger sisters have lower home-leaving risk than those with younger brothers, which is opposite the result for girls. This difference is at odds with Edmonds's labor supply estimates.

${ }^{42}$ See Garg and Morduch (1998), Morduch (2000), and Chen et al. (2010).
} 
directly — through productivity—and indirectly—because families are more likely to continue fertility after a girl than after a boy (Filmer et al. 2009). ${ }^{43}$ As a result, sibling sex composition may have multiple countervailing effects.

Many results in Section 5 address these theories. As a starting point, note that women with younger sisters appear to be worse-off than women with younger brothers, which makes allocative bias for sons an unlikely explanation for the effects. Son-biased fertility stopping rules, which are evident in Table 3, are more likely to play a role. However, several findings suggest that fertility stopping rules also fail to explain the sister effects observed in Section $5 .{ }^{44}$ First, the data suggest that older sisters have opposite effects from younger sisters on home-leaving. The alternative theories in the previous paragraph might predict that only older or younger siblings would matter-for example, because younger siblings do not yet work-but they do not give a natural interpretation for opposite effects. ${ }^{45}$ Second, the increase in family size due to twin boys is similar to that due to twin girls, but only the latter affect female home-leaving. These results imply that the younger sister effect is due to the presence of a sister rather than the absence of a brother. ${ }^{46}$ Third, in Figure 4 , the gap in school attendance between girls with younger sisters and brothers emerges only when girls are of marriageable age. Theories based on the value of sons would predict gaps in earlier childhood as well. For a broader look at this issue, Appendix Table 5 considers the effects of next-youngest sibling gender on four outcomes in earlier life: under-5 mortality, height and weight for two- to fouryear-olds, and school enrollment for five- to nine-year-olds. ${ }^{47}$ The results reveal little systematic evidence that the gender of a girl's next-youngest sibling affects her wellbeing in childhood.

\section{Sister Effects on Marriage Outside South Asia}

Because the family of origin is involved in marriage arrangements in many parts of the world, younger sisters may affect women's marriage age more globally. One would expect these sister

\footnotetext{
${ }^{43}$ The presence of a son may also improve a mother's bargaining power, with benefits to his sisters. The next paragraph discusses empirical patterns that reject this explanation.

${ }^{44}$ In addition to the findings discussed in this paragraph, the inclusion of childhood family size as a covariate did not substantively change the results. I do not report this finding in a table because completed family size is endogenous.

${ }^{45}$ The confidence intervals on the nonparametric bounds include zero, but the bounds themselves are both positive, and the OLS and selection-corrected estimates reject zero.

${ }^{46}$ Table 3 indicates that son-biased stopping rules are widespread, but they do explain the home-leaving patterns.

${ }^{47}$ Some of these variables do not appear in every survey. I analyze the heights and weights of two to four year-olds because the DHS only collects anthropometric data on children under 5, and few one-year-olds have a younger sibling. The height and weight z-scores have mean zero and standard deviation one in a "healthy" population.
} 
effects to be strongest in regions with the strictest adherence to parental arranged marriage, such as the Middle East, North Africa, Central Asia, and South Asia. In other world regions-such as Africa, East Asia, and Latin America-where the role of the family in marriage arrangements has declined, the effects may be smaller. Apart from Nepal, 40 other countries in Africa, Asia, and Latin America have conducted DHS surveys with questions on siblings, marriage, and education. Table 10 presents estimates of next-youngest sister effects on marriage risk and educational attainment in five world regions other than South Asia, using data on these 40 other countries. ${ }^{48}$

Column (1) reveals that younger sister effects on age at marriage are surprisingly prevalent throughout the developing world. As one would expect, in Afghanistan, Jordan, and Morocco, the Cox hazard ratios are similar in magnitude to those found in South Asia, ranging from 1.06 to 1.08. For Latin America, the Pacific, and Sub-Saharan Africa, the hazard ratios remain significantly greater than one, but they all lie between 1.01 and 1.02. These regional differences are consistent with the global diffusion of liberal attitudes towards marriage. Notably, dowry payments (net transfers from the bride's family) are extremely rare outside South Asia (Anderson 2007a), so the results reinforce the conclusion that dowry payments do not by themselves explain why younger sisters cause earlier marriage.

The table then examines whether these marriage age effects to translate into schooling effects, as they do in South Asia. For the schooling effects to operate, two conditions must be met: (1) marriage must occur at a sufficiently early age, and (2) school-leaving must occur at a sufficiently late age. As such, along with the hazard ratios for marriage and the OLS coefficients for educational attainment, the table reports the fraction of women who were married by age 16 and the fraction of women with no schooling.

Column (3) indicates that younger sisters have significant negative effects on educational attainment only in Sub-Saharan Africa. This result is easily squared with the distributions of marriage age and educational attainment. In Afghanistan, girls marry young but do not attend school for long, with an average of less than the second grade. In the Middle East and North Africa, they obtain more schooling but marry late. Early marriage is also fairly rare in Latin America and the Pacific. But the conditions are right for schooling effects in Sub-Saharan, where both early marriage and adolescent schooling are common. The effects on schooling are small, one-tenth the size of the

\footnotetext{
${ }^{48}$ The data from Indonesia and Jordan only include ever-married women, so I restrict both these samples to women over the age of 30 . For all other countries, the data include both married and unmarried women.
} 
effects in Nepal, but the effects on marriage risk are also small.

\section{Conclusions}

Traditional institutions interact in interesting ways with social and economic change. This paper studies how traditional marriage practices induce tradeoffs among sisters, tradeoffs most intense at intermediate levels of female schooling. Across four large South Asian countries, parents rush a daughter's marriage search if she has younger sisters and delay her marriage search if she has older sisters, at the expense of spousal quality. These effects are especially strong in settings where grooms are scarce, search frictions are large, and arranged marriage is common. Because girls leave school when they marry and depend on their husbands for economic support in adulthood, the effects have long-term consequences. In Nepal, where data on adult women are available, younger sisters cause earlier school-leaving, lower educational attainment and adult literacy, lower spousal educational attainment and spousal occupational status, and marginally lower adult household economic status. Sibling rivalry over leaving the nest has effects that last long after all siblings have left it.

These findings augment previous research on the lifecycle consequences of the marriage decision. In a notable paper on this topic, Field and Ambrus (2008) use age at menarche as an instrument for marriage age in rural Bangladesh, where girls may only enter the marriage market after reaching menarche. They find that women who started menstruating early married young and left school young but saw no change in spousal quality. Their different results on spousal quality highlight an important difference in the variation driving marriage age. In their study, early menarche leads to early marriage by expanding the opportunity set, thus allowing parents to find a weakly better groom. In mine, younger sisters lead to early marriage because they restrict the opportunity set. ${ }^{49}$

The policy implications of this result depend on the nature of the marriage market and the production function. If schooling has decreasing returns, then the cost of an older sister's lost time in school is greater than the benefit of her younger sister's gain. But perhaps more importantly, the theory predicts that the presence of any sister, older or younger, decreases expected spousal quality.

\footnotetext{
${ }^{49}$ Also consistent with my results, Field and Ambrus (2008) report that age at menarche has smaller effects on marriage age among women with more older sisters. However, their data only include siblings who survived to adulthood and as a result do not allow a more careful examination of sibling effects.
} 
If grooms attributes are equally valuable to all women, then the results imply a transfer of highquality grooms from large families to small. But if marriages are characterized by match-specific quality, then a large number of daughters per family may cause aggregate mismatch in the marriage market. Along these lines, the findings may provide a new justification for family planning policies (which on average reduce the number of daughters per family and increase the spacing between them), for the promotion of love marriage, or for the development of search technologies (e.g., matchmakers and websites).

The apparent role of search in explaining the results is surprising because it implies that for a large swath of the world's population, conventional budget constraint considerations fail to describe a principal cause of sibling rivalry. This finding suggests an interesting direction for future research, concerning how the interaction of persistent institutions with a changing economy shapes the effects of family structure on children's outcomes. It also calls attention to the question

of why some institutions evolve slowly, a topic raised by Roland (2005) and Guiso et al. (2006). A deeper understanding of these institutions and their effects may shed light on a range of social and economic phenomena, both across and within families.

\section{References}

Abramitzky, Ran, Adeline Delavande and Luís Vasconcelos. (2010). “Marrying Up: The Role of Sex Ratio in Assortative Matching." Mimeo, Stanford University.

Alesina, Alberto and Paola Giuliano. (2010). "The Power of the Family." Journal of Economic Growth 15(2): 93-125.

Ambrus, Attila, Erica Field and Máximo Torero. (2010). “Muslim Family Law, Prenuptial Agreements, and the Emergence of Dowry in Bangladesh." Quarterly Journal of Economics 125(3): 13491397.

Anderson, Siwan. (2007a). "The Economics of Dowry and Brideprice." Journal of Economic Perspectives 21(4): 151-174.

Angrist, Josh. (2002). “How Do Sex Ratios Affect Marriage and Labor Markets? Evidence from America's Second Generation." Quarterly Journal of Economics 117(3): 997-1038.

Angrist, Joshua, Victor Lavy, and Analia Schlosser. (2010). “Multiple Experiments for the Causal Link between the Quantity and Quality of Children." Journal of Labor Economics 28(4): 773-824. 
Arnold, Fred, Sunita Kishor, and T. K. Roy. 2002. "Sex-Selective Abortions in India." Population and Development Review 28(4): 759-785.

Bagnoli, Mark, and Ted Bergstrom. (2005). "Log-concave Probability and its Applications." Economic Theory 26(2): 445-469.

Becker, Gary S., and H. Gregg Lewis. (1973). “On the Interaction between the Quantity and Quality of Children." Journal of Political Economy 81: S279-S288.

Bertrand, Marianne, and Antoinette Schoar. (2006). "The Role of Family in Family Firms." Journal of Economic Perspectives 20(2): 73-96.

Bhalotra, Sonia, and Tom Cochrane. (2010). "Where Have All the Young Girls Gone? Identification of Sex Selection in India." Mimeo, Bristol University.

Black, Sandra, Paul J. Devereux, and Kjell G. Salvanes. (2005). "The More the Merrier? The Effect of Family Composition on Children's Education." Quarterly Journal of Economics 120: 669-700.

Blake, Judith. (1983). "Family Size and the Quality of Children." Demography 18: 421-442.

Botticini, Maristella, and Aloysius Siow. (2009). "Are There Increasing Returns to Scale in Marriage Markets?" Mimeo, Università Bocconi.

Butcher, Kristin F., and Anne Case. (1994). "The Effect of Sibling Sex Composition on Women's Education and Earnings." Quarterly Journal of Economics 109(3): 531-563.

Caldwell, John C., Pat Caldwell, Bruce K. Caldwell, and Idrani Pieres. (1998). "The Construction of Adolescence in a Changing World: Implications for Sexuality, Reproduction, and Marriage." Studies in Family Planning 29(2): 137-153.

Chen, Stacey H., Yen-Chien Chen, and Jin-Tan Liu. (2010). “The Effects of Sibling Sex Composition on Child Mortality and Education." Mimeo, Royal Holloway University of London.

Desai, Sonalde, and Lester Andrist. (2010). "Gender Scripts and Age at Marriage in India." Demography 47(3): 667-687.

Dillon, Lisa. (2010). "Parental and Sibling Influences on the Timing of Marriage, 17th and 18thCentury Quebec." Annales de Dèmographie Historique 119: 139-180.

Edlund, Lena. (1999). "Son Preference, Sex Ratios, and Marriage Patterns." Journal of Political Economy 107(6): 1275-1304.

Edlund, Lena, and Nils-Petter Lagerlöf. (2006). "Individual vs. Parental Consent in Marriage: Implications for Intra-Household Resource Allocation and Growth." Mimeo, Columbia University.

Edmonds, Eric. (2006). “Understanding Sibling Differences in Child Labor." Journal of Population Economics 19: 795-821. 
Fafchamps, Marcel, and Agnes R. Quisumbing. (2007). “Household Formation and Marriage Markets in Rural Areas." In T. Paul Schultz and John A. Strauss, eds., Handbook of Development Economics, Volume 4. Amsterdam: Elsevier.

Field, Erica, and Attila Ambrus. (2008). "Early Marriage, Age of Menarche, and Female Schooling Attainment in Bangladesh." Journal of Political Economy 116(5): 881-930.

Filmer, Deon, Jed Friedman, and Norbert Schady. (2009). “Development, Modernization, and Childbearing: The Role of Family Sex Composition." World Bank Economic Review 23(3): 371-398.

Garg, Ashish, and Jonathan Morduch. (1998). "Sibling Rivalry and the Gender Gap: Evidence from Child Health Outcomes in Ghana." Journal of Population Economics 11(4): 471-493.

Goldberger, Arthur. (1983). “Abnormal Selection Bias.” In Samuel Karlin, Takeshi Amemiya, and Leo A. Goodman, eds., Studies in Econometrics, Time Series, and Multivariate Statistics. NewYork: Academic Press, pp. 67-84.

Goode, William Josiah. (1970). World Revolution and Family Patterns. New York: Free Press.

Goody, Jack R. (1983). The Development of the Family and Marriage in Europe. New York: Cambridge University Press.

Greif, Avner. (1994). "Cultural Beliefs and the Organization of Society: a Historical and Theoretical Reflection on Collectivist and Individualist Societies." Journal of Political Economy 102: 912-950.

Guiso, Luigi, Paola Sapienza, and Luigi Zingales. 2006. “Does Culture Affect Economic Outcomes?" Journal of Economic Perspectives 20(2): 23-48.

Gurung, Ganesh Man and Tove C. Kittelsen. (1986). "Kurma, Kola, and Kuli as Community Concepts: Patrilineage, Deities, and Inside-Outside Dichotomy among the Rana Tharus." In Emerging Ethnicity and Aspects of Community Adaptation. Kathmandu: Central Department of Sociology and Anthropology, Tribhuvan University, pp. 78-93.

Heckman, James J. (1974). "Shadow Prices, Market Wages and Labor Supply." Econometrica 42: 679694.

Heckman, James. (1979). "Sample Selection Bias as a Specification Error." Econometrica 47(1): 153162.

Horowitz, Joel L., and Charles F. Manski. (2000). “Nonparametric Analysis of Randomized Experiments with Missing Covariate and Outcome Data." Journal of the American Statistical Association 95: 77-84.

Jacoby, Hanan and Ghazala Mansuri. (2010). “Watta Satta: Exchange Marriage and Women's Welfare in rRural Pakistan." American Economic Review 100(4): 1804-25.

Kaestner, Robert. (1997). "Are Brothers Really Better? Sibling Sex Composition and Educational Attainment Revisited." Journal of Human Resources 32: 250-84. 
Lee, David S. (2009). “Training, Wages, and Sample Selection: Estimating Sharp Bounds on Treatment Effects." Review of Economic Studies 76(3): 1071-1102.

Li, Hongbin, Junsen Zhang, and Yi Zhu. (2008). "The Quantity-Quality Tradeoff of Children in a Developing Country: Identification Using Chinese Twins." Demography 45(1): 223-243.

Majupuria, Indra and Trilok Chandra Majupuria. (1978). Marriage Customs in Nepal: Ethnic Groups, their Marriage Customs and Traditions. Kathmandu: Indra Majupuria.

Morduch, Jonathan. (2000). "Sibling Rivalry in Africa." American Economic Review 90(2): 405-409.

Munshi, Kaivan, and Mark Rosenzweig. (2006). "Traditional Institutions Meet the Modern World: Caste, Gender, and Schooling Choice in a Globalizing Economy." American Economic Review 96(4): 1225-1252.

Nepal Central Bureau of Statistics. (2010). National Population Census 2001. In Minnesota Population Center, Integrated Public Use Microdata Series, International: Version 6.0 [Machine-readable database]. Minneapolis: University of Minnesota.

Niraula, Bhanu B., and S. Philip Morgan. (1996). "Marriage Formation, Post-Marital Contact with Natal Kin and Autonomy of Women: Evidence from Two Nepali Settings." Population Studies 50: 35-50.

Parish, William L., and Robert J. Willis. (1993). “Daughters, Education, and Family Budgets: Taiwan Experiences." Journal of Human Resources 28(4): 863-898.

Petrongolo, Barbara, and Christopher A. Pissarides. (2001). "Looking into the Black Box: A Survey of the Matching Function." Journal of Economic Literature 39(2): 390-431.

Pew Research Center. (2009). Mapping the Global Muslim Population: A Report on the Size and Distribution of the World's Muslim Population. Washington, DC.

Pörtner, Claus. (2010). "Sex-Selective Abortions, Fertility, and Birth Spacing." Mimeo, University of Washington.

Rao, Vijayendra. (1993). “The Rising Price of Husbands: A Hedonic Analysis of Dowry Increases in Rural India." Journal of Political Economy 101(4): 666-677.

Roland, Gérard. (2003). “Understanding Institutional Change: Fast-Moving and Slow-Moving Institutions." Studies in Comparative International Development 38(4): 109-131.

Rosenzweig, Mark R., and Kenneth I. Wolpin. (1980). "Testing the Quantity-Quality Fertility Model: The Use of Twins as a Natural Experiment." Econometrica 48: 227-240.

Rosenzweig, Mark R., and Junsen Zhang. (2009). "Do Population Control Policies Induce More Human Capital Investment? Twins, Birth Weight, and China's 'One Child' Policy." Review of Economic Studies 76: 1149-74. 
Sah, Nepali. "How Useful are the Demographic Surveys in Explaining the Determinants of Early Marriage of Girls in the Terai of Nepal?" Journal of Population Research 25(2): 207-222.

Smith, Daniel Scott. (1973). "Parental Power and Marriage Patterns: An Analysis of Historical Trends in Hingham, Massachusetts." Journal of Marriage and the Family 35 (3): 406-415.

Steelman, Lala Carr, Brian Powell, Regina Werum, and Scott Carter. (2002). "Reconsidering the Effects of Sibling Configuration: Recent Advances and Challenges." Annual Review of Sociology 28: 243-269.

Tertilt, Michele. (2005). “Polygyny, Fertility, and Savings." Journal of Political Economy 113(6): 134171.

Trivers, Robert L., and Dan E. Willard. (1973). "Natural Selection of Parental Ability to Vary the Sex-Ratio of Offspring." Science 179(4068): 90-92.

United Nations Children's Fund (UNICEF). (2001). Early Marriage: Child Spouses. Florence, Italy: UNICEF, Innocenti Research Center.

Vytlacil, Edward. (2002). “Independence, Monotonicity, and Latent Index Models: An Equivalence Result." Econometrica 70: 331-341.

Weber, Max. (1905). The Protestant Ethic and the Spirit of Capitalism. London: Routledge Classic. 
Figure 1

Parental Coresidence by Age and Sex-Specific Birth Order
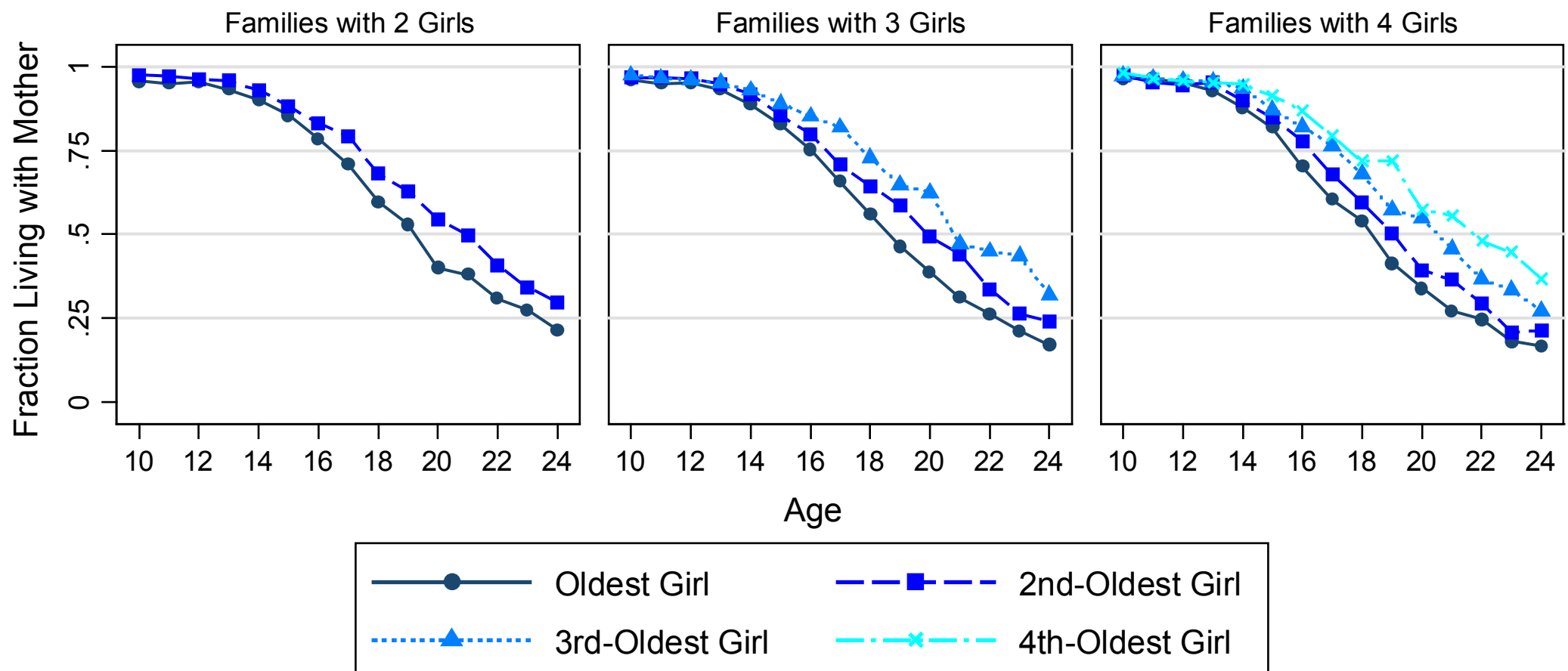

Notes: Number of obs. from two-girl families $=66,684$; from three-girl families $=53,187$; from four-girl families $=31,671$. Data sources are listed in Appendix Table 1. 
Figure 2

Parental Coresidence by Sex of Next-Youngest Sibling

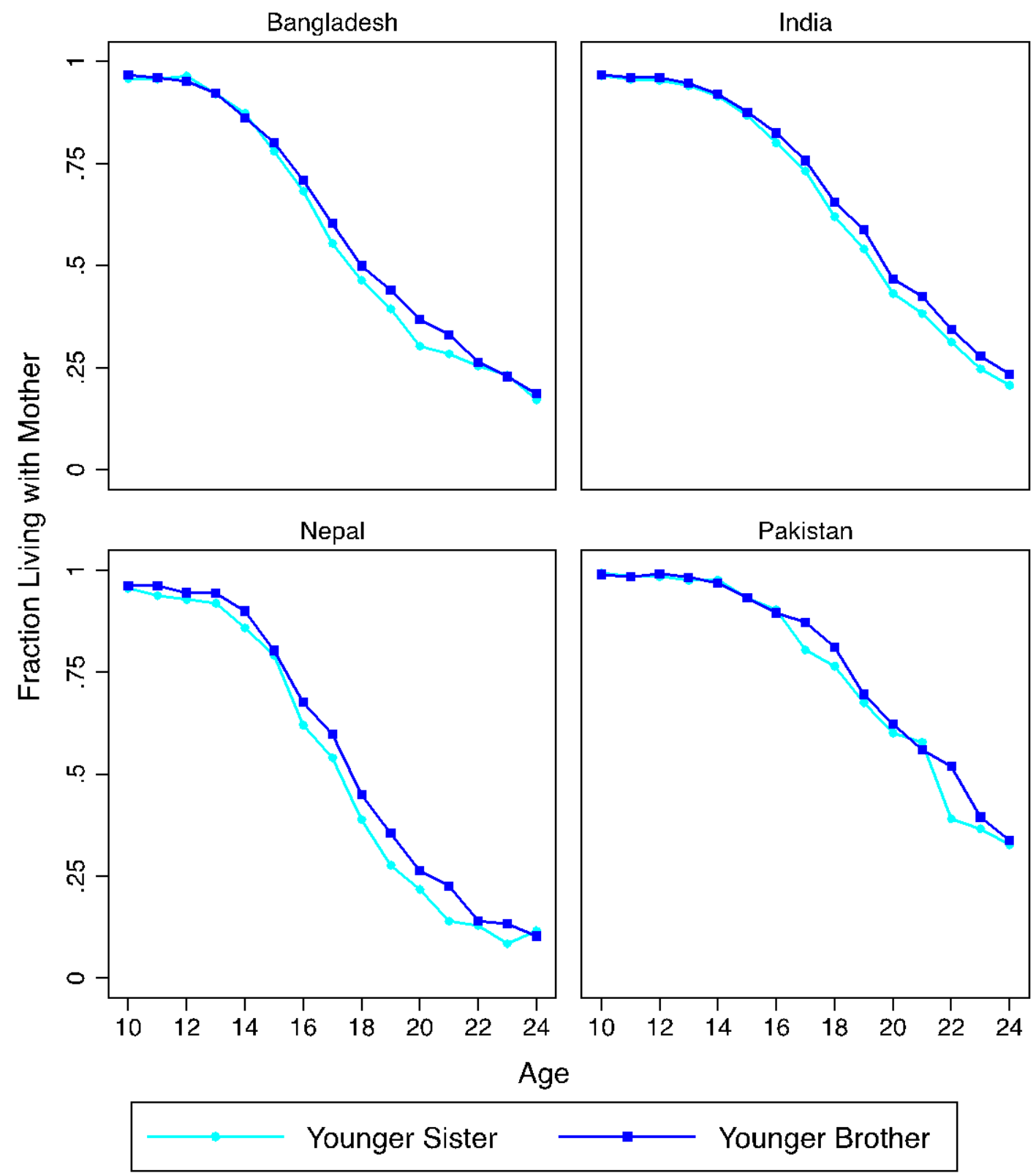

Notes: Samples include surviving girls with at least one ever-born younger sibling. Current and next multiple births are excluded. Sample sizes: India = 149,650; Bangladesh = 29,244; Nepal = 15,107; Pakistan $=12,539$. Data sources are listed in Appendix Table 1. 
Figure 3

Younger Sister Effects on Parental Coresidence by Age, Pooled Data

\section{A. $1^{\text {st }}$ Subsequent Pregnancy}

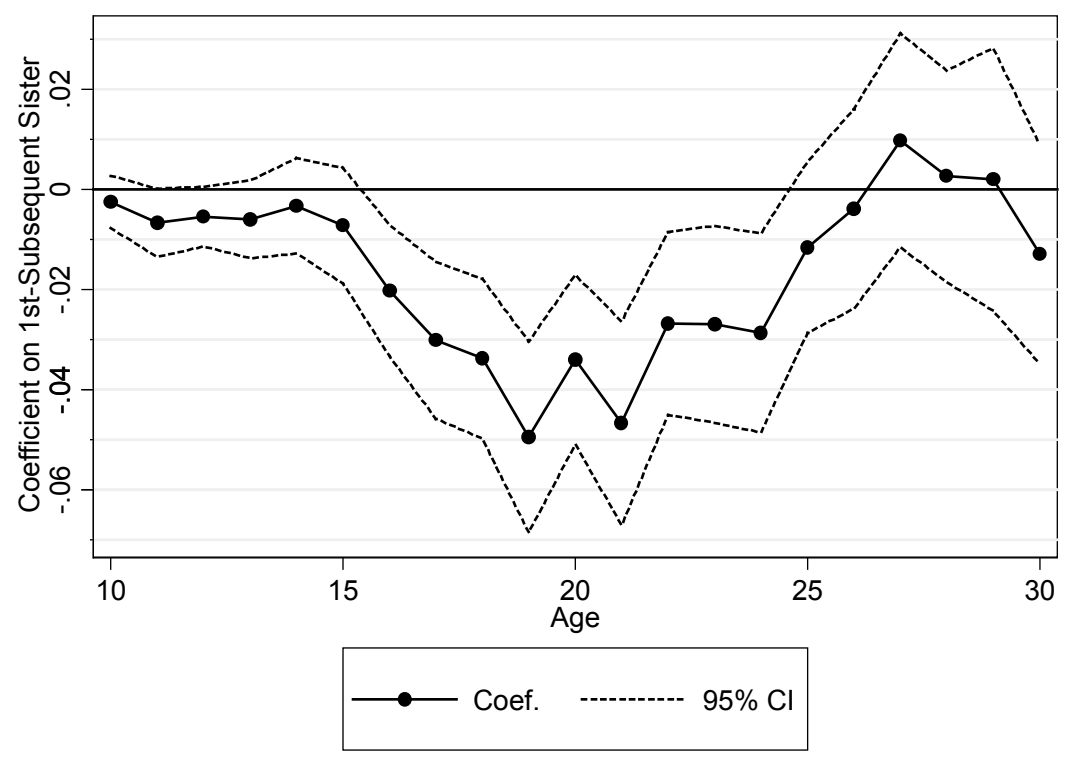

B. 2nd Subsequent Pregnancy

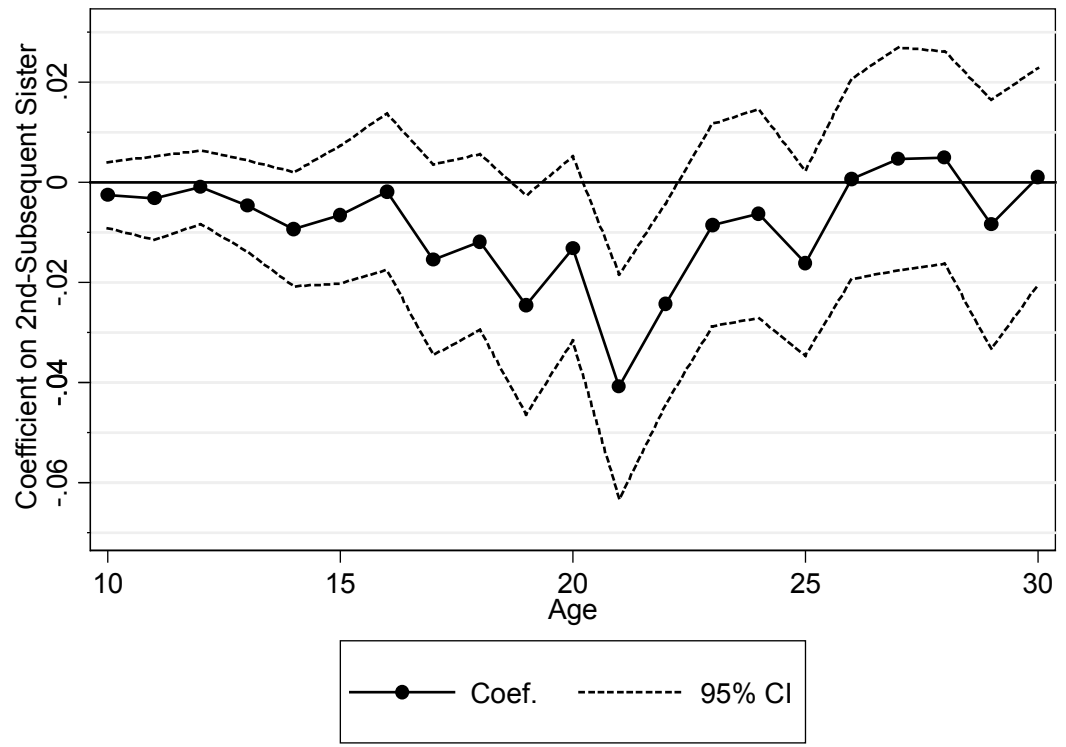

Notes: The figure plots coefficients from age-specific estimations of equation (3). In Panel A, the sample includes surviving girls with at least one ever-born younger sibling. In Panel B, the sample includes surviving girls with at least two ever-born younger siblings. Current and subsequent multiple births are excluded. Data sources are listed in Appendix Table 1. 
Figure 4

Home-Leaving, Marriage, and Schooling by Sex of Next-Youngest Sibling, Nepal

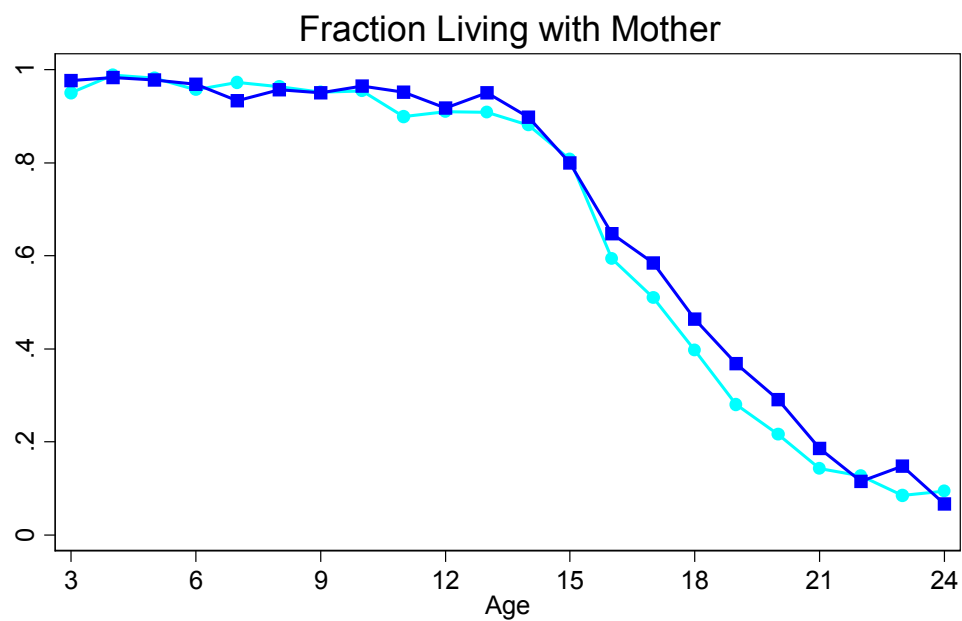

Fraction Never Married

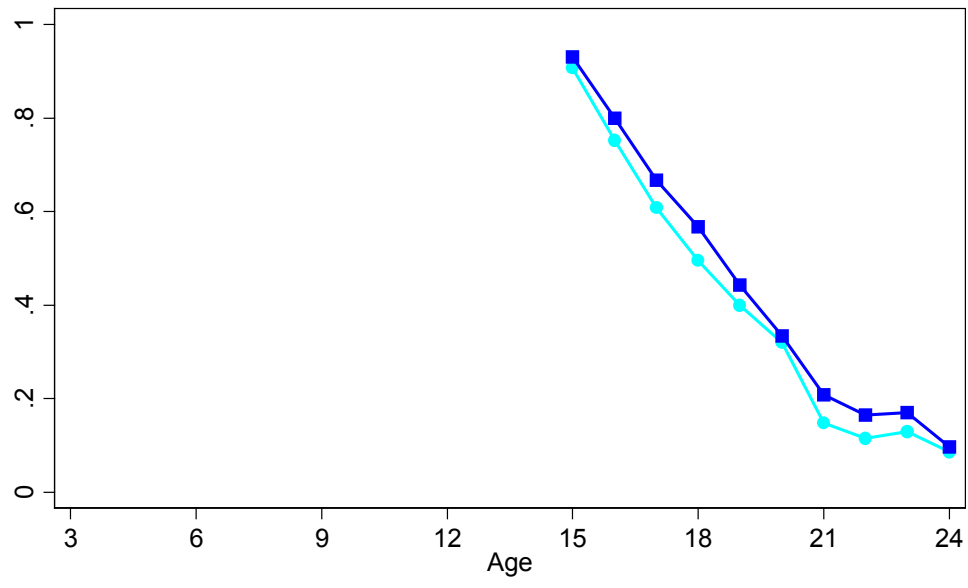

Fraction Attending School in Last Year

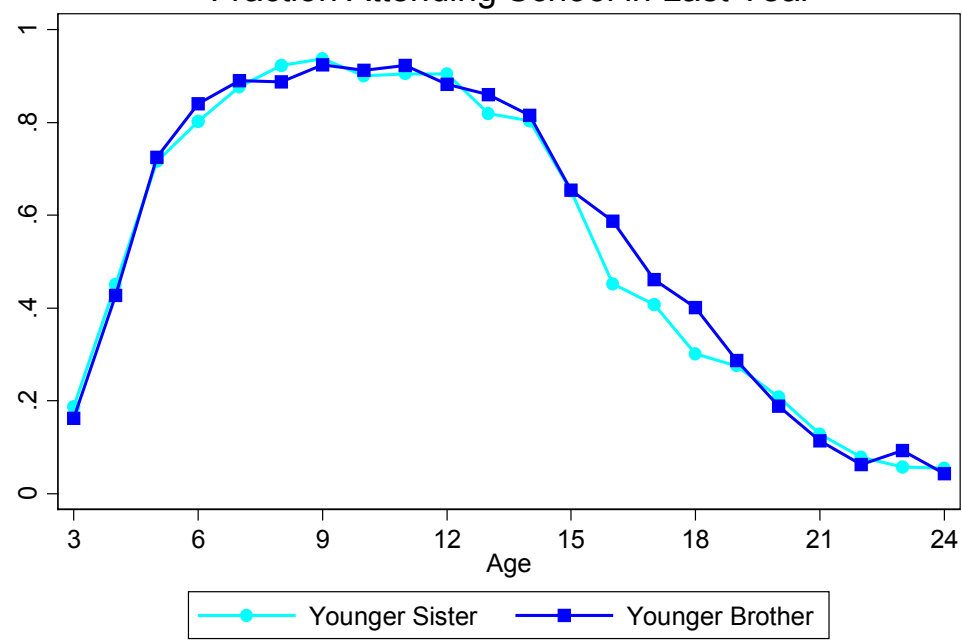

Notes: Sample includes females with at least one younger sibling. The top panel is based on Fertility Histories. The middle panel is based on Sibling Histories. The bottom panel is based on Fertility Histories for ages 3-14 and Sibling Histories for ages 15-24. Source: 2006 Nepal DHS. 
Table 1

Younger Sister Effects on Parental Coresidence, Women Aged 15-24

\begin{tabular}{|c|c|c|c|c|}
\hline & $\begin{array}{c}\text { Bangladesh } \\
(1)\end{array}$ & $\begin{array}{c}\text { India } \\
(2)\end{array}$ & $\begin{array}{l}\text { Nepal } \\
(3)\end{array}$ & $\begin{array}{c}\text { Pakistan } \\
(4)\end{array}$ \\
\hline \multicolumn{5}{|c|}{ A. $1^{\text {st }}$ Subsequent Pregnancy (Conditional on $\geq 1$ More Pregnancy) } \\
\hline Younger Sister & $\begin{array}{l}-0.035 \\
{[0.007]}\end{array}$ & $\begin{array}{l}-0.027 \\
{[0.003]}\end{array}$ & $\begin{array}{l}-0.037 \\
{[0.010]}\end{array}$ & $\begin{array}{l}-0.028 \\
{[0.011]}\end{array}$ \\
\hline $\begin{array}{l}\text { Mean Among Women } \\
\text { w/ a Younger Brother }\end{array}$ & 0.49 & 0.59 & 0.44 & 0.73 \\
\hline Number of Obs. & 14,650 & 77,589 & 7,542 & 6,211 \\
\hline \multicolumn{5}{|c|}{ B. $2^{\text {nd }}$ Subsequent Pregnancy (Conditional on $\geq 2$ More Pregnancies) } \\
\hline Younger Sister & $\begin{array}{l}-0.015 \\
{[0.008]}\end{array}$ & $\begin{array}{c}-0.014 \\
{[0.004]}\end{array}$ & $\begin{array}{l}-0.015 \\
{[0.010]}\end{array}$ & $\begin{array}{l}-0.010 \\
{[0.011]}\end{array}$ \\
\hline $\begin{array}{l}\text { Mean Among Women } \\
\text { w/ a Younger Brother }\end{array}$ & 0.46 & 0.55 & 0.41 & 0.72 \\
\hline Number of Obs. & 11,881 & 58,647 & 6,453 & 5,677 \\
\hline \multicolumn{5}{|c|}{$\begin{array}{l}\text { Notes: OLS estimates. Brackets contain standard errors clustered at the PSU-level. Only observa- } \\
\text { tions with singleton current and subsequent births are included. Each cell reports a coefficient from a } \\
\text { separate regression. The dependent variable equals one if the woman resides with her mother, zero } \\
\text { otherwise. All regressions include fixed effects for age, mother's region of residence, survey year, } \\
\text { and the exact composition of older siblings by birth order and sex. Regressions also control for } \\
\text { spacing from the previous birth, maternal and paternal educational attainment, maternal age, and } \\
\text { rural residence. Data sources are listed in Appendix Table } 1 \text {. }\end{array}$} \\
\hline
\end{tabular}


Table 2

Next-Youngest Sister Effects on Parental Coresidence, Selected Subsamples, Women Aged 15-24, Pooled Data

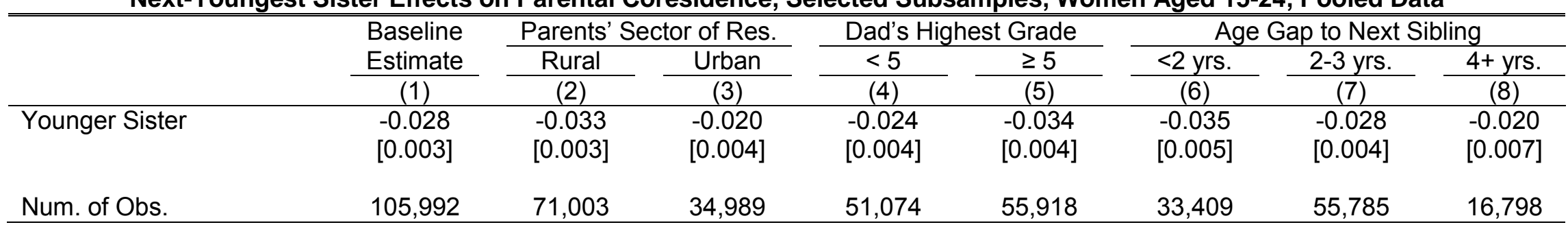

Notes: OLS estimates. Brackets contain standard errors clustered at the PSU-level. The sample includes young women with at least one ever-born younger sibling. Only observations with singleton current and next births are included. Each cell reports a coefficient from a separate regression. The dependent variable equals one if the woman resides with her mother and zero otherwise. All regressions include fixed effects for age, mother's region of residence, survey year, and the exact composition of older siblings by birth order and sex. Regressions also control for spacing from the previous birth, maternal and paternal educational attainment, maternal age, and rural residence. Data sources are listed in Appendix Table 1. 
Table 3

Effects of Younger Twins, Women Aged 15-24, Pooled Data

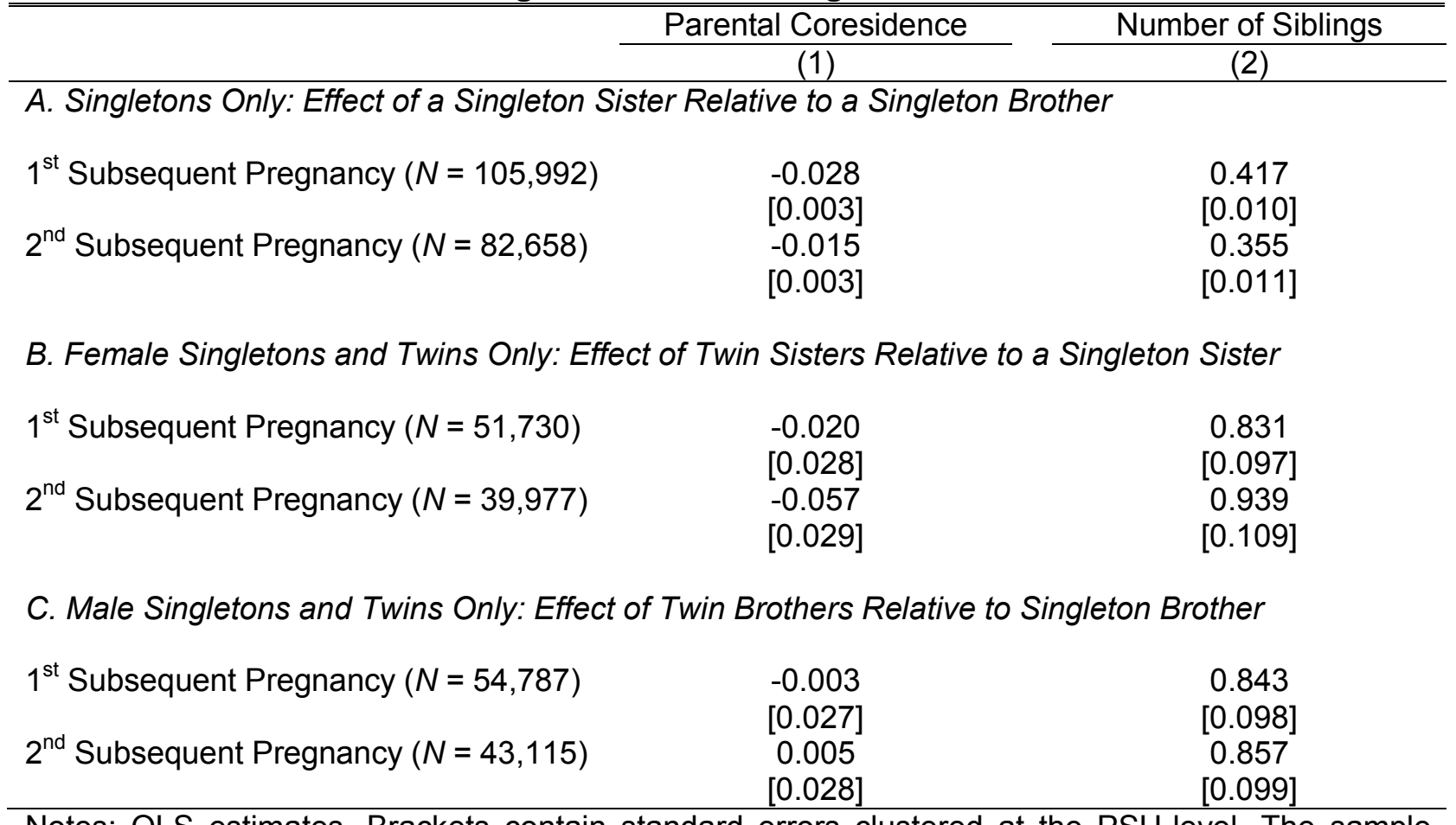
Notes: OLS estimates. Brackets contain standard errors clustered at the PSU-level. The sample includes young women whose mothers had at least one or two subsequent pregnancies, depending on the specification. Each cell reports a coefficient from a separate regression. All regressions include fixed effects for age, survey (country-by-year), and the exact composition of older siblings by birth order and sex. Regressions also control for spacing from the previous birth, maternal and paternal educational attainment, maternal age, religion, and rural residence. Data sources are listed in Appendix Table 1. 
Table 4

Next-Youngest Sister Effects and Marriage Market Demography, Women Aged 15-24, Nepal

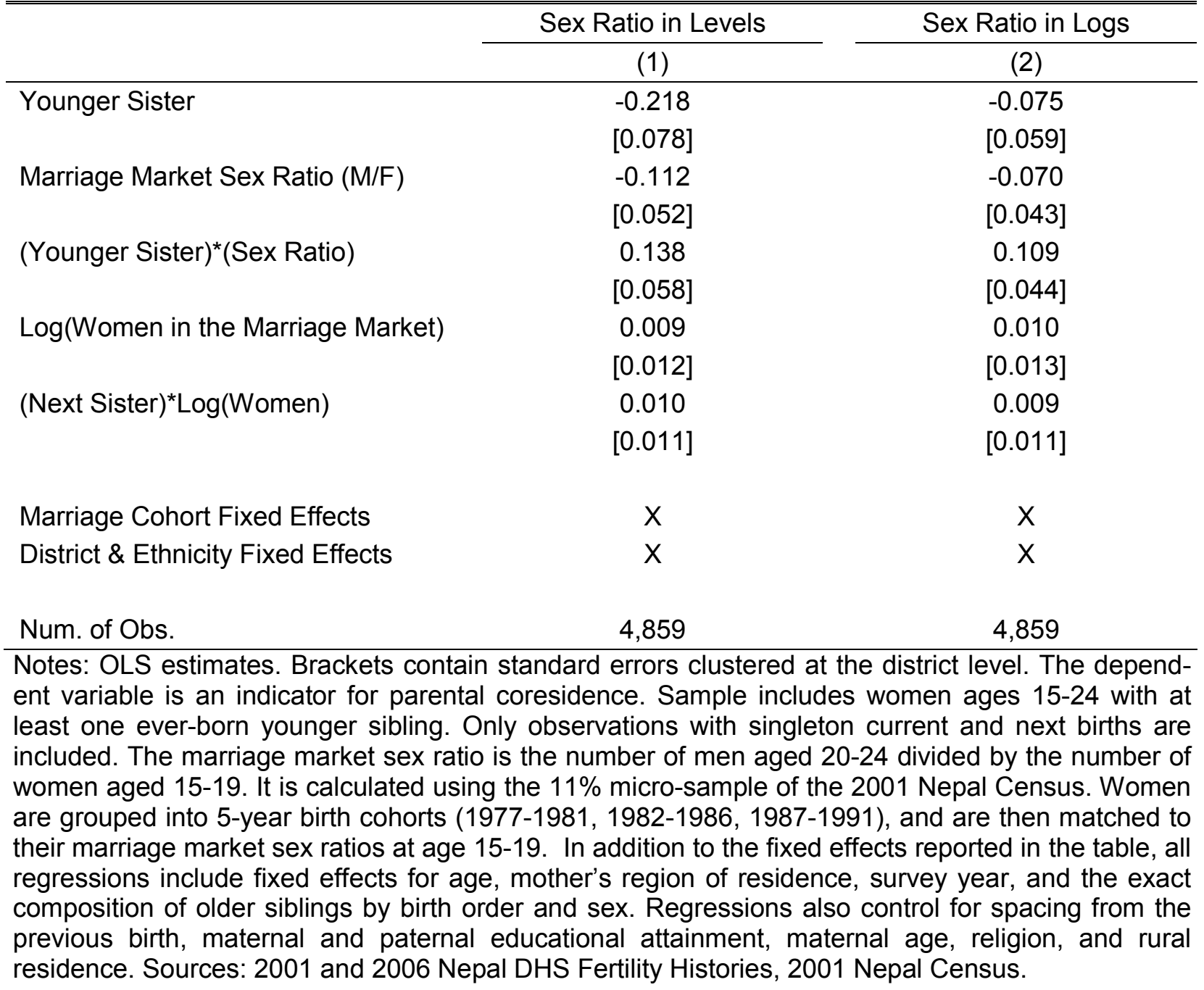


Table 5

Next-Youngest Sister Effects and the Prevalence of Arranged Marriage, Women Aged 15-24, India

\begin{tabular}{|c|c|c|c|c|}
\hline & $(1)$ & $(2)$ & $(3)$ & $(4)$ \\
\hline \multirow[t]{2}{*}{ Younger Sister } & -0.039 & -0.047 & -0.049 & -0.065 \\
\hline & [0.011] & [0.012] & [0.017] & [0.020] \\
\hline \multirow[t]{2}{*}{ District Share of Women Aged 25-29 with Self-Arranged Marriages } & & 0.056 & & -0.041 \\
\hline & & [0.076] & & [0.074] \\
\hline \multirow[t]{2}{*}{ 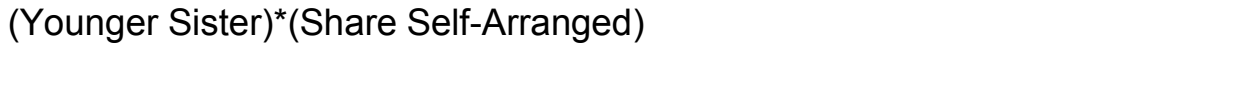 } & & 0.158 & & 0.189 \\
\hline & & [0.086] & & [0.093] \\
\hline \multirow[t]{2}{*}{ District Share of Women Aged 25-29 with No Say in Marriage Arrangements } & & & -0.113 & -0.118 \\
\hline & & & [0.030] & [0.032] \\
\hline \multirow[t]{2}{*}{ 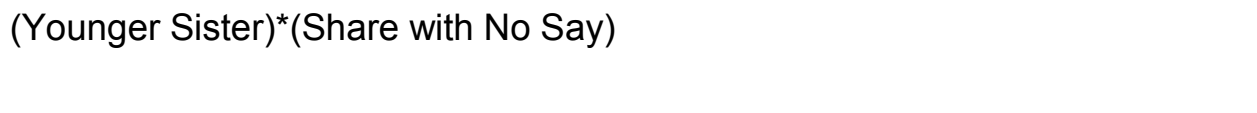 } & & & 0.028 & 0.048 \\
\hline & & & [0.034] & [0.037] \\
\hline Num. of Obs. & 16,154 & 16,154 & 16,154 & 16,154 \\
\hline \multicolumn{5}{|c|}{$\begin{array}{l}\text { Notes: OLS estimates. Brackets contain standard errors clustered at the PSU-level. The dependent variable is an indicator for parent } \\
\text { coresidence. Sample includes women ages } 15-24 \text { with at least one ever-born younger sibling. Only observations with singleton current an } \\
\text { next births are included. The district shares are estimated within the same survey dataset, based on respondents' reports of their ow } \\
\text { marriage arrangements. All regressions include fixed effects for age and the exact composition of older siblings by birth order and ser } \\
\text { Regressions also control for spacing from the previous birth, maternal and paternal educational attainment, maternal age, and religion } \\
\text { Source: } 2005 \text { India Human Development Survey. }\end{array}$} \\
\hline
\end{tabular}


Table 6

Next-Youngest vs. Next-Oldest Sister Effects on Parental Coresidence, Women Aged 15-24, Pooled Data

\begin{tabular}{|c|c|c|c|c|c|c|c|}
\hline & \multirow{3}{*}{$\begin{array}{c}\text { Effect of } \\
\text { Younger } \\
\text { Sister (OLS) } \\
(1)\end{array}$} & \multicolumn{6}{|c|}{ Effect of Older Sister } \\
\hline & & OLS & $\begin{array}{l}\text { Heckman } \\
(1974)\end{array}$ & $\begin{array}{l}\text { Heckman } \\
(1974)\end{array}$ & $\begin{array}{c}\text { Avg. Trimming } \\
\text { Proportion } \\
\end{array}$ & $\begin{array}{c}\text { Lee (2009) } \\
\text { Lower Bound }\end{array}$ & $\begin{array}{c}\text { Lee (2009) } \\
\text { Upper Bound }\end{array}$ \\
\hline & & (2) & (3) & $(4)$ & (5) & $(6)$ & $(7)$ \\
\hline $1^{\text {st }}$ Birth Order & $\begin{array}{l}-0.027 \\
{[0.004]}\end{array}$ & - & - & - & - & - & - \\
\hline $2^{\text {nd }}$ Birth Order & $\begin{array}{l}-0.029 \\
{[0.005]}\end{array}$ & $\begin{array}{c}0.013 \\
{[0.004]}\end{array}$ & - & - & $\begin{array}{c}0.032 \\
{[0.010]}\end{array}$ & $\begin{array}{c}0.001 \\
{[0.007]}\end{array}$ & $\begin{array}{c}0.032 \\
{[0.009]}\end{array}$ \\
\hline $3^{\text {rd }}$ Birth Order & $\begin{array}{l}-0.037 \\
{[0.006]}\end{array}$ & $\begin{array}{c}0.0124 \\
{[0.0056]}\end{array}$ & $\begin{array}{c}0.0143 \\
{[0.0068]}\end{array}$ & $\begin{array}{c}0.0105 \\
{[0.0066]}\end{array}$ & $\begin{array}{c}0.028 \\
{[0.012]}\end{array}$ & $\begin{array}{c}0.006 \\
{[0.008]}\end{array}$ & $\begin{array}{c}0.033 \\
{[0.010]}\end{array}$ \\
\hline $4^{\text {th }}$ Birth Order & $\begin{array}{l}-0.027 \\
{[0.008]}\end{array}$ & $\begin{array}{c}0.030 \\
{[0.007]}\end{array}$ & $\begin{array}{c}0.033 \\
{[0.008]}\end{array}$ & $\begin{array}{c}0.033 \\
{[0.008]}\end{array}$ & $\begin{array}{c}0.087 \\
{[0.017]}\end{array}$ & $\begin{array}{c}0.001 \\
{[0.010]}\end{array}$ & $\begin{array}{c}0.091 \\
{[0.012]}\end{array}$ \\
\hline $5^{\text {th }}$ Birth Order & $\begin{array}{l}-0.019 \\
{[0.011]}\end{array}$ & $\begin{array}{c}0.020 \\
{[0.010]}\end{array}$ & $\begin{array}{c}0.030 \\
{[0.011]}\end{array}$ & $\begin{array}{c}0.028 \\
{[0.011]}\end{array}$ & $\begin{array}{c}0.110 \\
{[0.022]}\end{array}$ & $\begin{array}{l}-0.023 \\
{[0.015]}\end{array}$ & $\begin{array}{c}0.102 \\
{[0.018]}\end{array}$ \\
\hline Own age & $15-24$ & $15-24$ & $15-24$ & $15-24$ & $15-24$ & $15-24$ & $15-24$ \\
\hline Older sib's age & - & Any & $16-25$ & $16-25$ & $16-25$ & $16-25$ & $16-25$ \\
\hline Younger sib's age & Any & - & - & - & - & - & - \\
\hline Covariates: & & & & & & & \\
\hline Older sibling comp. & $\mathrm{X}$ & $\mathrm{X}$ & $\mathrm{X}$ & $\mathrm{X}$ & $X$ & $X$ & $\mathrm{X}$ \\
\hline M's age at $1^{\text {st }}$ birth & $\mathrm{X}$ & $\mathrm{x}$ & $X$ & $\mathrm{X}$ & & & \\
\hline Other parental vars. & $\mathrm{X}$ & $\mathrm{X}$ & & $\mathrm{X}$ & & & \\
\hline
\end{tabular}

Notes: Brackets contain standard errors. Other parental variables include the mother's age at first marriage, the mother's educational attainment, and the father's educational attainment. Columns (1) and (2) report OLS estimates of the coefficient on a dummy indicating that the specified (singleton) sibling is female, conditional on that sibling ever being born, with standard errors clustered at the PSU-level. Columns (3)-(4) show Heckman selection-corrected coefficients on the next-oldest sister dummy, estimated by maximum likelihood with standard errors clustered at the PSU-level. The excluded instrument is the mother's age at the older sibling's birth. The Heckman models are not estimable for second-born children because the mother's age at first birth is the same as the mother's age at the older sibling's birth. Columns (5)-(7) implement Lee's (2009) trimming procedure to estimate nonparametric bounds on older sister effects, which are stratified by the exact composition of older siblings (not counting the next-oldest). Column (5) reports the average trimming proportion across the strata, with standard errors that are computed using the delta method and are clustered at the PSU-level. Columns (4) and (5) report the corresponding upper and lower bounds on the effect of a next-oldest sister, with standard errors that are block bootstrapped at the PSU-level. Data sources are listed in Appendix Table 1. 
Table 7

Next-Youngest Sister Effects on Women Aged 15-19, Nepal

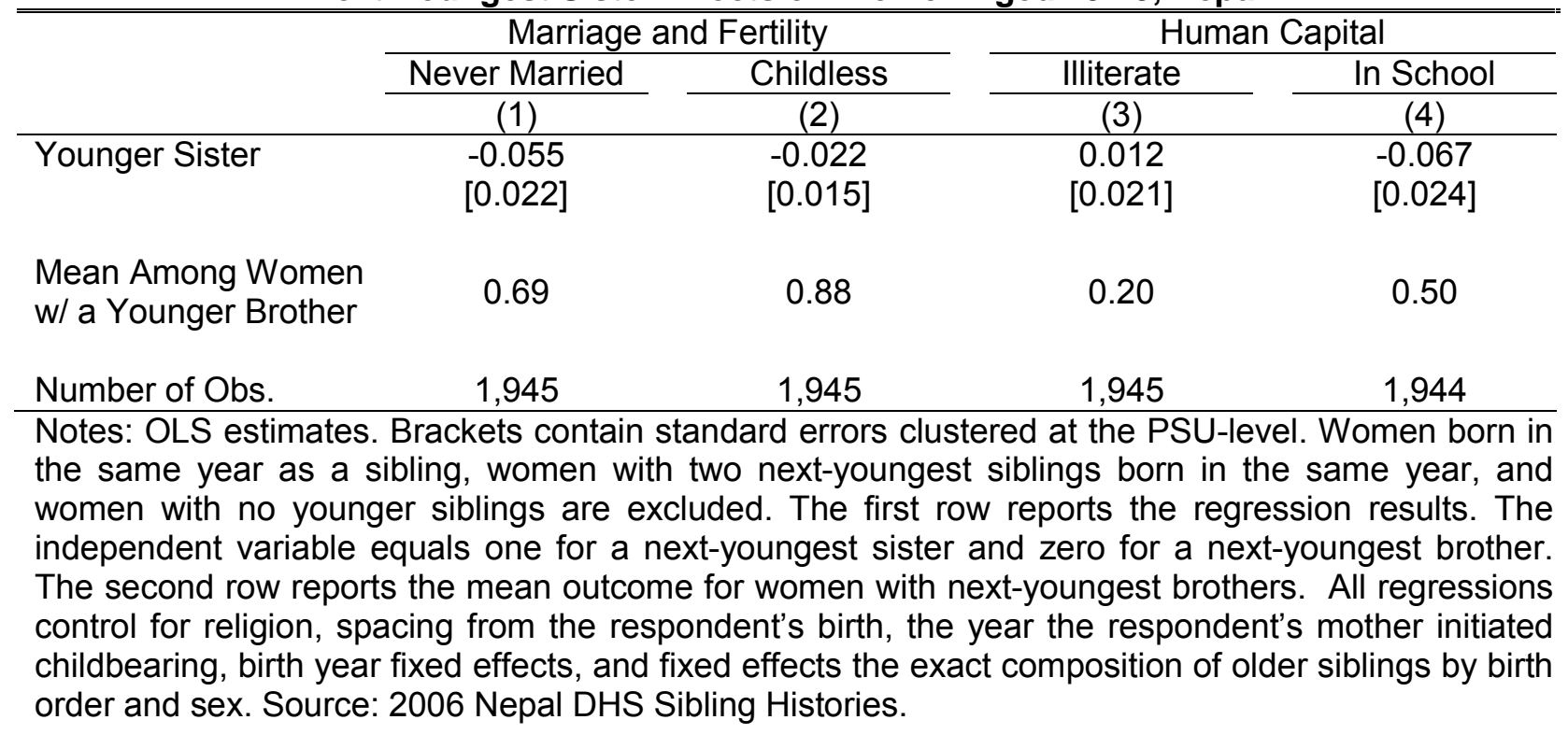


Table 8

Next-Youngest Sister Effects on Women Aged 15-49, Nepal

\begin{tabular}{|c|c|c|c|c|c|c|c|c|}
\hline \multicolumn{9}{|c|}{ Panel A. All Women Aged 15-49, 2006 DHS } \\
\hline & \multicolumn{3}{|c|}{$\begin{array}{c}\text { Marriage and Fertility } \\
\text { (Cox Hazard Ratios) }\end{array}$} & \multicolumn{2}{|c|}{$\begin{array}{c}\text { Human Capital } \\
\text { (OLS Coefficients) }\end{array}$} & \multicolumn{3}{|c|}{$\begin{array}{c}\text { Health } \\
\text { (OLS Coefficients) } \\
\end{array}$} \\
\hline & \multicolumn{2}{|c|}{ Marriage } & $1^{\text {st }}$ Birth & $\begin{array}{l}\text { Highest } \\
\text { Grade }\end{array}$ & Illiterate & & BMI $\left(m / k^{2}\right)$ \\
\hline & \multicolumn{2}{|l|}{$(1)$} & $(2)$ & $(3)$ & $(4)$ & \multicolumn{2}{|c|}{$(5)$} & (6) \\
\hline Younger Sister & \multicolumn{2}{|c|}{$\begin{array}{c}1.116 \\
{[0.025]}\end{array}$} & $\begin{array}{c}1.127 \\
{[0.027]}\end{array}$ & $\begin{array}{l}-0.146 \\
{[0.078]}\end{array}$ & $\begin{array}{c}0.029 \\
{[0.010]}\end{array}$ & \multicolumn{2}{|c|}{$\begin{array}{c}0.090 \\
{[0.129]}\end{array}$} & $\begin{array}{l}-0.122 \\
{[0.071]}\end{array}$ \\
\hline $\begin{array}{l}\text { Mean Among Women } \\
\text { w/ a Younger Brother }\end{array}$ & \multicolumn{2}{|l|}{0.11} & 0.08 & 3.18 & 0.44 & \multicolumn{2}{|c|}{150.89} & 20.69 \\
\hline Number of Obs. & \multicolumn{2}{|c|}{8,706} & 8,706 & 8,706 & \multirow[t]{2}{*}{8,701} & \multicolumn{2}{|c|}{8,669} & 8,667 \\
\hline \multicolumn{8}{|c|}{ Panel B. Ever-Married Women Aged 30-49, 1996 and 2006 DHS } & \\
\hline & \multicolumn{2}{|c|}{$\begin{array}{c}\text { Marriage and Fertility } \\
\text { (Cox Hazard Ratios) }\end{array}$} & \multicolumn{2}{|c|}{$\begin{array}{l}\text { Own Human Capital } \\
\text { (OLS Coefficients) }\end{array}$} & \multicolumn{4}{|c|}{$\begin{array}{l}\text { Match Attributes } \\
\text { (OLS Coefficients) }\end{array}$} \\
\hline & Marriage & $1^{\text {st }}$ Birth & $\begin{array}{l}\text { Highest } \\
\text { Grade }\end{array}$ & Illiterate & $\begin{array}{l}\text { H's } \\
\text { Grade }\end{array}$ & $\begin{array}{l}\text { H Skilled } \\
\text { Occ. }\end{array}$ & H's Age & $\begin{array}{l}\text { Asset } \\
\text { Index }\end{array}$ \\
\hline & $(7)$ & $(8)$ & $(9)$ & $(10)$ & $(11)$ & $(12)$ & $(13)$ & $(14)$ \\
\hline Younger Sister & $\begin{array}{c}1.056 \\
{[0.022]}\end{array}$ & $\begin{array}{c}1.063 \\
{[0.024]}\end{array}$ & $\begin{array}{l}-0.150 \\
{[0.068]}\end{array}$ & $\begin{array}{c}0.029 \\
{[0.011]}\end{array}$ & $\begin{array}{l}-0.215 \\
{[0.100]}\end{array}$ & $\begin{array}{l}-0.044 \\
{[0.012]}\end{array}$ & $\begin{array}{l}-0.044 \\
{[0.148]}\end{array}$ & $\begin{array}{l}-0.044 \\
{[0.026]}\end{array}$ \\
\hline $\begin{array}{l}\text { Mean Among Women } \\
\text { w/ a Younger Brother }\end{array}$ & 0.15 & 0.09 & 1.09 & 0.73 & 4.03 & 0.40 & 43.06 & 0.02 \\
\hline Number of Obs. & 6,877 & 6,877 & 6,877 & 6,873 & 6,672 & 6,772 & 6,329 & 6,877 \\
\hline \multicolumn{9}{|c|}{$\begin{array}{l}\text { Notes: Brackets contain standard errors clustered at the PSU-level. Women born in the same year as a sibling, women with two next- } \\
\text { youngest siblings born in the same year, and women with no younger siblings are excluded. The first row of each panel reports the regres- } \\
\text { sion results. The independent variable equals one for a next-youngest sister and zero for a next-youngest brother. The second row of each } \\
\text { panel reports the mean outcome for women with next-youngest brothers; for the Cox models, the row reports the mean hazard during ages } \\
10-30 \text {. All regressions control for religion, spacing from the respondent's birth, the year the respondent's mother initiated childbearing, and } \\
\text { birth and survey year fixed effects. The OLS regressions include fixed effects for the exact composition of older siblings by birth order and } \\
\text { sex; the Cox models stratify by this variable (so as not to impose proportionality). Source: } 1996 \text { and } 2006 \text { Nepal DHS Sibling Histories. }\end{array}$} \\
\hline
\end{tabular}


Table 9

Next-Youngest Sister Effects and Dowries, Women Aged 15-24, Nepal and India

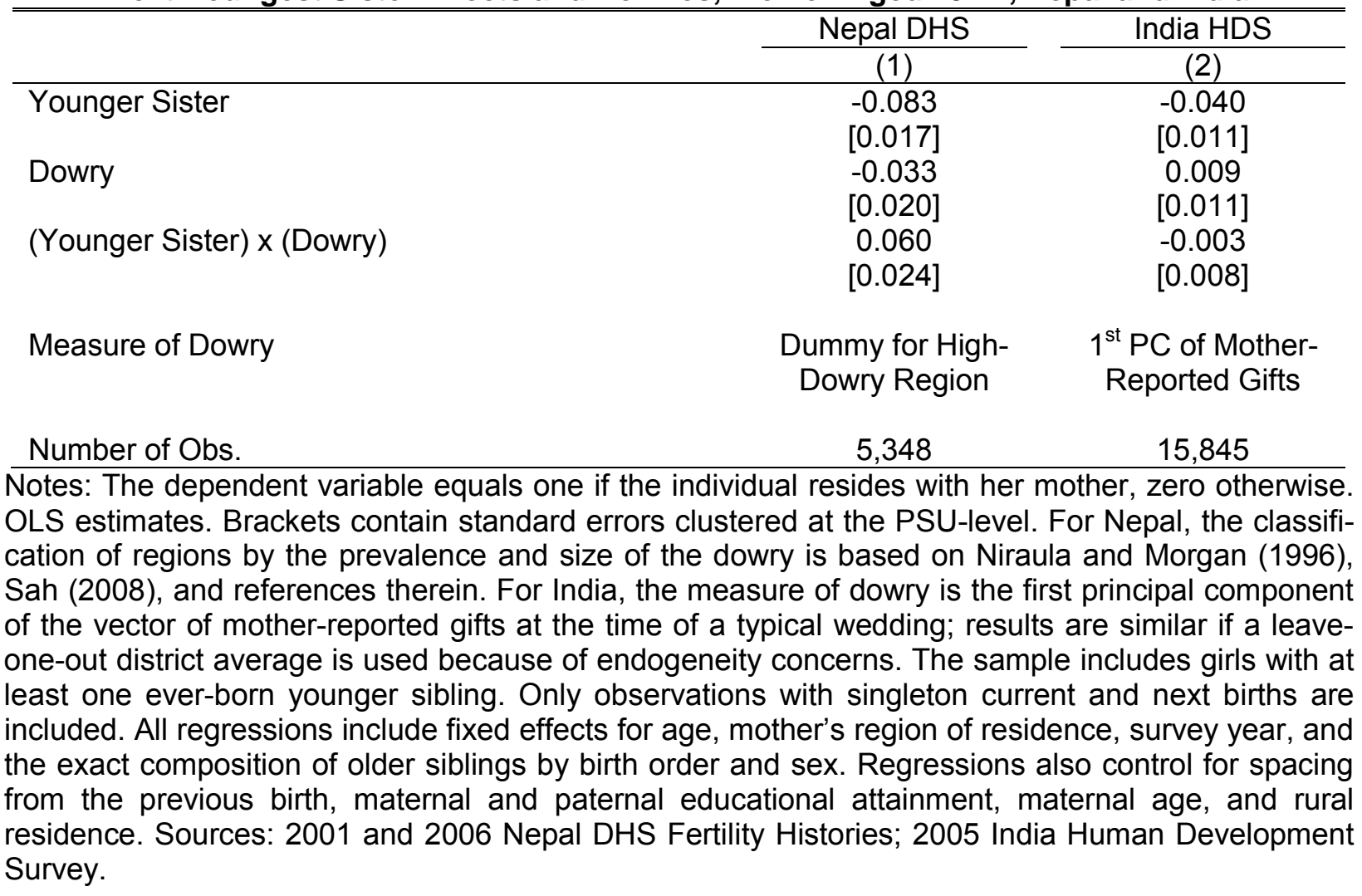


Table 10

Next-Youngest Sister Effects on Marriage and Education Outside South Asia

\begin{tabular}{|c|c|c|c|c|}
\hline & \multicolumn{2}{|c|}{ Age at Marriage } & \multicolumn{2}{|c|}{ Highest Grade } \\
\hline & \multirow{2}{*}{$\begin{array}{c}\text { Cox HR } \\
\text { (1) }\end{array}$} & \multirow{2}{*}{$\begin{array}{c}\text { \% Married } \\
\text { by Age } 16 \\
(2)\end{array}$} & \multirow{2}{*}{$\begin{array}{c}\text { OLS } \\
\text { Coef. } \\
(3)\end{array}$} & \multirow{2}{*}{$\begin{array}{c}\% \text { w/ No } \\
\text { School } \\
(4)\end{array}$} \\
\hline & & & & \\
\hline Southeast Asia/Pacific $(N=116,178)$ & 1.020 & $20 \%$ & -0.021 & $15 \%$ \\
\hline (Cambodia, Indonesia, Philippines) & {$[0.0061]$} & & [0.023] & \\
\hline Central Asia $(N=39,465)$ & 1.083 & $29 \%$ & 0.016 & $73 \%$ \\
\hline (Afghanistan) & [0.015] & & [0.040] & \\
\hline Middle East and North Africa $(N=22,986)$ & 1.058 & $18 \%$ & 0.002 & $53 \%$ \\
\hline (Jordan, Morocco) & [0.016] & & [0.056] & \\
\hline Latin America and the Caribbean $(N=167,237)$ & 1.016 & $19 \%$ & -0.004 & $8 \%$ \\
\hline (Bolivia, Dominican Republic, Haiti, Peru) & {$[0.0056]$} & & [0.021] & \\
\hline Sub-Saharan Africa $(N=396,400)$ & 1.018 & $32 \%$ & -0.028 & $46 \%$ \\
\hline (Benin, Burkina Faso, Cameroon, CAR, Chad, DRC, & [0.0035] & & [0.012] & \\
\hline Congo, Cote D'Ivore, Ethiopia, Gabon, Ghana, & & & & \\
\hline Guinea, Kenya, Lesotho, Madagascar, Malawi, Mali, & & & & \\
\hline Mozambique, Namibia, Nigeria, Rwanda, Sao Tome & & & & \\
\hline \& Principe, Senegal, Sierra Leone, South Africa, & & & & \\
\hline Swaziland, Tanzania, Togo, Zambia, Zimbabwe) & & & & \\
\hline
\end{tabular}

Notes: Brackets contain standard errors clustered at the PSU-level. Women born in the same year as a sibling, women with two next-youngest siblings born in the same year, and women with no younger siblings are excluded. The independent variable equals one for a next-youngest sister and zero for a next-youngest brother. The Cox regressions stratify by birth order-by-country interactions, as well as control for spacing from the respondent's birth, birth year dummies, and survey year dummies. The OLS regressions control for spacing from the respondent's birth, birth year dummies, survey year dummies, and birth order-by-country interactions. Column (2) reports the fraction of women married before their $17^{\text {th }}$ birthdays. All countries with DHS surveys containing sibling histories and age-at-marriage are included. 


\section{Theory Appendix}

\section{Derivation of One-Daughter Solution}

In each period, the groom either arrives $(A)$ or not $(N)$. Let $V_{o}^{A}(q, a)$ be the value function associated with groom offer $q$ at age $a$, and let $V_{o}^{N}(a)$ be the value function when no groom arrives. Then:

$$
\begin{gathered}
V_{o}^{N}(a)=\mathbb{E}\left[\lambda V_{o}^{A}(q, a+1)+(1-\lambda) V_{o}^{N}(a+1)\right] \\
V_{o}^{A}(q, a)=\max \left\{q, \mathbb{E}\left[\lambda V_{o}^{A}(q, a+1)+(1-\lambda) V_{o}^{N}(a+1)\right]\right\}
\end{gathered}
$$

Because the problem is non-stationary, the optimal policy involves setting an age-dependent reservation quality $q_{o}(a)$. We solve for $q_{o}(a)$ using backward induction. At $a=\bar{a}$ :

$$
q_{o}(\bar{a})=0 \quad V_{o}^{N}(\bar{a})=0 \quad \mathbb{E} V_{o}^{A}(q, \bar{a})=\mathbb{E} q
$$

Then at $a<\bar{a}$ :

$$
\begin{gathered}
q_{o}(a)=\mathbb{E}\left[\lambda V_{o}^{A}(q, a+1)+(1-\lambda) V_{o}^{N}(a+1)\right] \\
V_{o}^{N}(a)=\mathbb{E}\left[\lambda V_{o}^{A}(q, a+1)+(1-\lambda) V_{o}^{N}(a+1)\right] \\
\mathbb{E} V_{o}^{A}(a)=\int_{\underline{Q}}^{q_{o}(a)} q_{o}(a) d F(\tilde{q})+\int_{q_{o}(a)}^{\bar{Q}} \tilde{q} d F(\tilde{q})
\end{gathered}
$$

which yields the recursive solution:

$$
\begin{gathered}
q_{o}(a)-q_{o}(a+1)=\lambda\left(1-F\left[q_{o}(a+1)\right]\right)\left(\mathbb{E}\left[q \mid q>q_{o}(a+1)\right]-q_{o}(a+1)\right) \equiv \lambda \psi\left(q_{o}(a+1)\right) \\
q_{o}(\bar{a})=0
\end{gathered}
$$

Note that the transition function $\lambda \psi(\cdot)$ is positive, so $q_{o}(a)>q_{o}(a+1)$ for all $a<\bar{a}$. Furthermore:

$$
\frac{d \psi}{d q_{o}(a+1)}=-f\left(q_{o}(a+1)\right)\left(\mathbb{E}\left[q \mid q>q_{o}(a+1)\right]-q_{o}(a+1)\right)+\left(1-F\left[q_{o}(a+1)\right]\right)\left(\frac{d \mathbb{E}\left[q \mid q>q_{o}(a+1)\right]}{d q_{o}(a+1)}-1\right)
$$

assuming that the density of $F$ exists. The first term is negative. The second is of ambiguous sign, but if $q$ is log-concave, then $\frac{d \mathbb{E}\left[q \mid q>q_{o}(a+1)\right]}{d q_{o}(a+1)} \leq 1$ (Goldberger 1983), so that the second term is weakly negative. Therefore, if $q$ is log-concave, $\psi$ decreases in $q_{0}(a+1)$. 


\section{Derivation of Two-Daughter Solution}

For a family with two daughters, the option value of an unmarried younger daughter is always greater than the option value of an unmarried elder daughter. As long as both daughters are still of marriageable age, the parents will always opt to marry the elder daughter before her younger sister. After the elder daughter is married, the younger daughter's marriage problem reduces to the one-daughter problem, and so $q_{y}(a)=q_{o}(a)$. For the elder daughter, the value functions and the reservation quality now also vary with the sibling age gap $\Delta$ :

$$
\begin{gathered}
V_{e}^{N}(a, \Delta)=\mathbb{E}\left[\lambda V_{e}^{A}(q, a+1, \Delta)+(1-\lambda) V_{e}^{N}(a+1, \Delta)\right] \\
V_{e}^{A}(q, a, \Delta)=\max \left\{q+V_{y}^{N}(a-\Delta), \mathbb{E}\left[\lambda V_{e}^{A}(q, a+1, \Delta)+(1-\lambda) V_{e}^{N}(a+1, \Delta)\right]\right\}
\end{gathered}
$$

As in the one-daughter case, we solve for $q_{e}(a, \Delta)$ using backward induction. At $a=\bar{a}$ :

$$
q_{e}(\bar{a}, \Delta)=0 \quad \mathbb{E} V_{e}^{N}(\bar{a}, \Delta)=q_{y}(\bar{a}-\Delta) \quad \mathbb{E} V_{e}^{A}(q, \bar{a}, \Delta)=\mathbb{E} q+q_{y}(\bar{a}-\Delta)
$$

Then at $a<\bar{a}$ :

$$
\begin{gathered}
q_{e}(a, \Delta)+q_{y}(a-\Delta)=\mathbb{E}\left[\lambda V_{e}^{A}(q, a+1, \Delta)+(1-\lambda) V_{e}^{N}(a+1, \Delta)\right] \\
V_{e}^{N}(a, \Delta)=\mathbb{E}\left[\lambda V_{e}^{A}(q, a+1, \Delta)+(1-\lambda) V_{e}^{N}(a+1, \Delta)\right] \\
\mathbb{E} V_{e}^{A}(a, \Delta)=\int_{\underline{Q}}^{q_{e}(a, \Delta)} q_{e}(a, \Delta) d F(\tilde{q})+\int_{q_{e}(a, \Delta)}^{\bar{Q}} \tilde{q} d F(\tilde{q})+q_{y}(a-\Delta)
\end{gathered}
$$

which yields the recursive solution:

$$
\begin{gathered}
q_{e}(a, \Delta)-q_{e}(a+1, \Delta)=\lambda \psi\left(q_{e}(a+1, \Delta)\right)-\left(q_{y}(a-\Delta)-q_{y}(a-\Delta+1)\right) \\
q_{e}(\bar{a}, \Delta)=0
\end{gathered}
$$

Note that this solution differs from the only-daughter and younger daughter solutions only through the last (subtracted) term, $q_{y}(a-\Delta)-q_{y}(a-\Delta+1)$, which is positive. 


\section{Proof of Result}

(a) A girl with a younger sister has higher cumulative marriage risk at any given age.

Let $P_{i}(a)$ be the cumulative probability of marriage by age $a$ for a daughter of type $i$. Because $q_{e}(a, \Delta)<q_{o}(a)$ for all $a<\bar{a}$ and all $\Delta>0$, the failure rate $1-F\left[q_{i}(\cdot)\right]$ is higher for an elder daughter than for an only daughter. As a result $P_{e}(a)>P_{o}(a)$ for all $a<\bar{a}$.

(b) A girl with an older sister has lower cumulative marriage risk at any given age.

For an only daughter, we have that:

$$
P_{o}(a)=\sum_{\tilde{a}=\underline{a}}^{a}\left(\lambda\left[1-F\left[q_{o}(\tilde{a})\right]\right] \prod_{s=\underline{a}}^{\tilde{a}-1}\left[1-\lambda+\lambda F\left[q_{o}(s)\right]\right]\right)
$$

Recall that $q_{y}(a)=q_{0}(a)$ but that a younger daughter must wait at least one period for her older sister to marry. Thus:

$$
P_{y}(a) \leq \sum_{\tilde{a}=\underline{a}+1}^{a}\left(\lambda\left[1-F\left[q_{o}(\tilde{a})\right]\right] \prod_{s=\underline{a}+1}^{\tilde{a}-1}\left[1-\lambda+\lambda F\left[q_{o}(s)\right]\right]\right)
$$

Because $q_{o}(a)$ strictly declines with $a, P_{o}(a)>P_{y}(a)$ for all $a$.

(c) A girl with either an older or younger sister has lower expected spousal quality.

Let $\mathbb{E}_{i}\left[q_{i} \mid a=\tilde{a}\right]$ denote expected spousal quality at the start of age $\tilde{a}$ for $i \in 0, y$, and let $\mathbb{E}_{i}\left[q_{i} \mid a=\right.$ $\tilde{a}, \Delta=\tilde{\Delta}]$ denote the same for $i=e$. Assume that spinsterhood is equivalent to a spouse of quality zero. For an only daughter, we have that:

$$
\mathbb{E}_{o}\left[q_{o} \mid a=\underline{a}\right]=\sum_{\tilde{a}=\underline{a}}^{\bar{a}}\left(\lambda \mathbb{E}\left[q \mid q>q_{o}(a+1)\right]\left[1-F\left[q_{o}(\tilde{a})\right]\right] \prod_{s=\underline{a}}^{a-1}\left[1-\lambda+\lambda F\left[q_{o}(s)\right]\right]\right)
$$

Recall again that a girl with an older sister must wait at least one period for her older sister to marry. Thus:

$$
\mathbb{E}_{y}\left[q_{y} \mid a=\underline{a}\right] \leq \sum_{\tilde{a}=\underline{a}+1}^{\overline{\bar{a}}}\left(\lambda \mathbb{E}\left[q \mid q>q_{o}(a+1)\right]\left[1-F\left[q_{o}(\tilde{a})\right]\right] \prod_{s=\underline{a}+2}^{a-1}\left[1-\lambda+\lambda F\left[q_{o}(s)\right]\right]\right)
$$

Again because $q_{o}(a)$ strictly declines with $a, \mathbb{E}_{o}>\mathbb{E}_{y}$.

To prove that an older daughter has lower expected quality than an only daughter, note that:

$$
\mathbb{E}_{o}\left[q_{o} \mid a=\underline{a}\right]=\mathbb{E}\left[\lambda V_{o}^{A}(q, \underline{a}+1)+(1-\lambda) V_{o}^{N}(\underline{a}+1)\right]=q_{o}(\underline{a}-1)
$$


For an elder daughter:

$$
\begin{aligned}
\mathbb{E}_{e}\left[q_{e}+V_{o}^{N}(a+1) \mid a=\underline{a}, \Delta=\tilde{\Delta}\right] & =\mathbb{E}\left[\lambda V_{e}^{A}(q, \underline{a}+1, \tilde{\Delta})+(1-\lambda) V_{o}^{N}(\underline{a}+1, \tilde{\Delta})\right] \\
& =q_{e}(\underline{a}-1, \tilde{\Delta})+q_{y}(\underline{a}-1-\tilde{\Delta})
\end{aligned}
$$

And thus:

$$
\mathbb{E}_{e}\left[q_{e} \mid a=\underline{a}, \Delta=\tilde{\Delta}\right]=q_{e}(\underline{a}-1, \tilde{\Delta})
$$

Because $q_{e}(\underline{a}-1, \tilde{\Delta})<q_{o}(\underline{a}-1)$ for all $\tilde{\Delta}>0$, we have that $\mathbb{E}_{o}>\mathbb{E}_{e}$. 


\section{Appendix Tables and Figures}

Appendix Figure 1

\section{Early Marriage by Sex of Next-Youngest Sibling, Nepal}

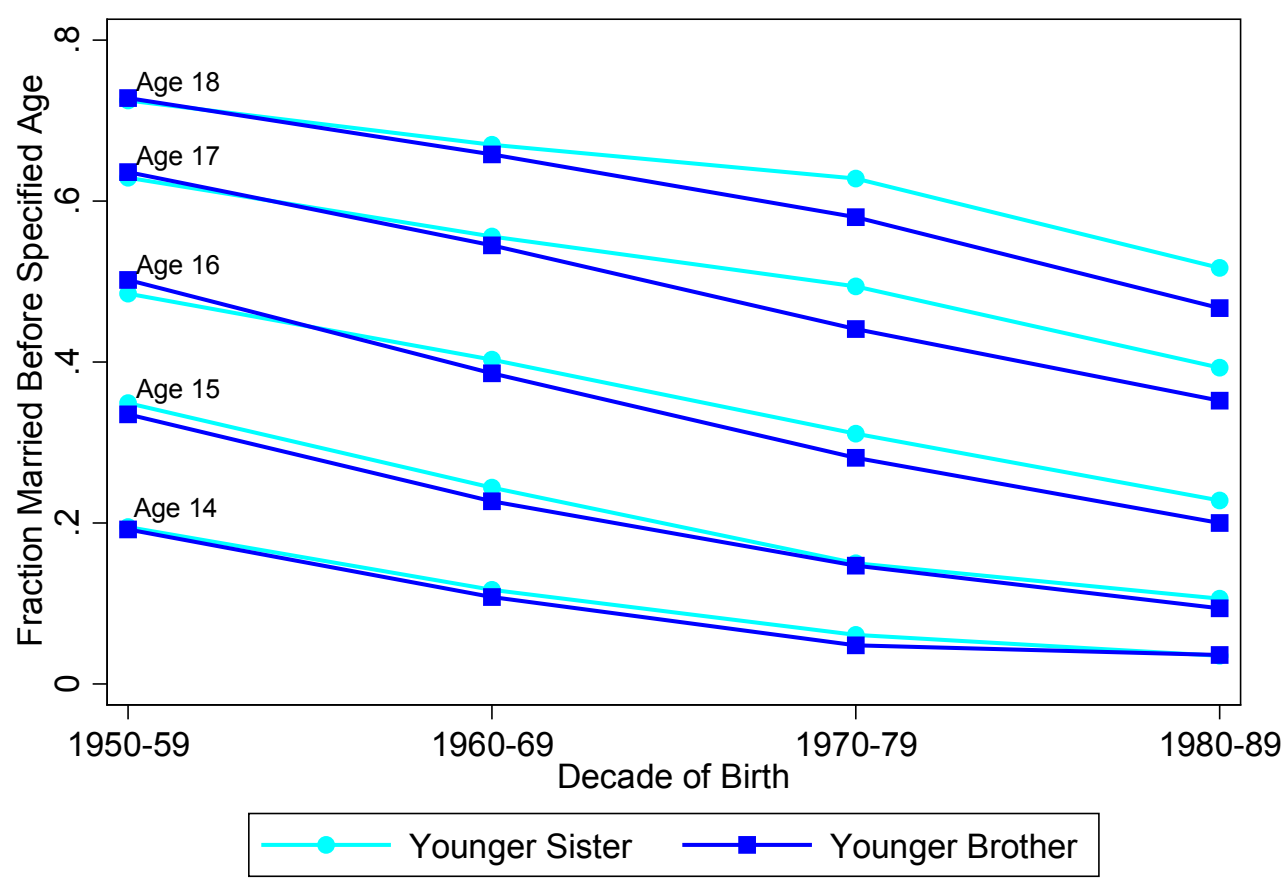

Notes: Sample includes all women aged 15-49 from the 2006 Nepal DHS and ever-married women aged 30-49 from the 1996 Nepal DHS. Women with no younger siblings are excluded, as are women born in the same year as a sibling and women with two next-youngest siblings born in the same year. 
Appendix Table 1

Demographic and Health Surveys Used in the Fertility History Analysis

Country:

Bangladesh

India

Nepal

Pakistan
Survey year:

1993-94, 1996-97, 1999-2000, 2004, 2007

1992-93, 1998-99, 2005-06

1996, 2001, 2006

1990-91, 2006-07 
Appendix Table 2

Unadjusted Estimates of Next-Youngest Sister Effects

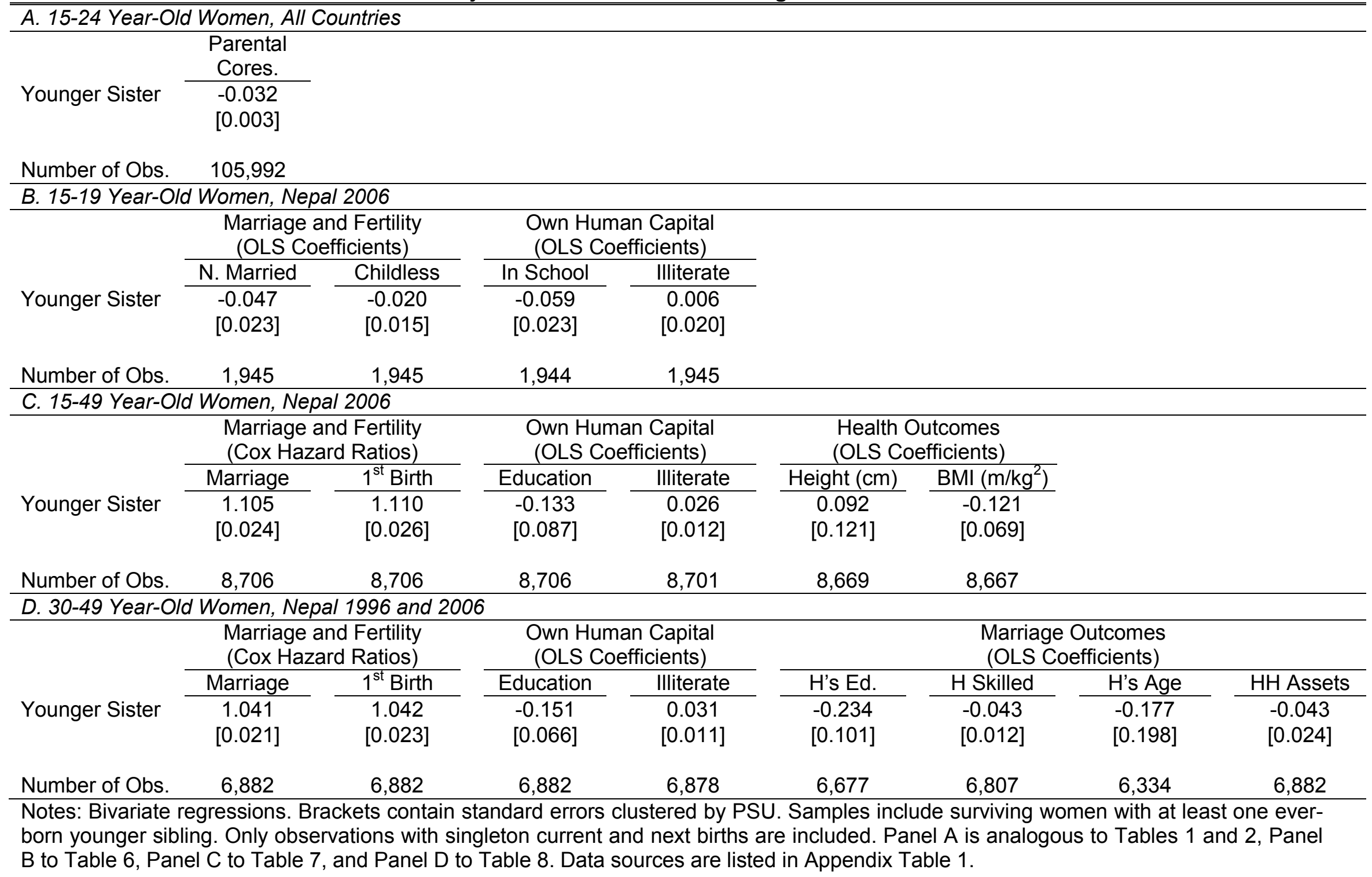


Appendix Table 3

Predictors of Next-Youngest Sisters, Women Aged 15-24

\begin{tabular}{|c|c|c|c|c|}
\hline & $\frac{\text { Bangladesh }}{(1)}$ & $\frac{\text { India }}{(2)}$ & $\frac{\text { Nepal }}{(3)}$ & $\frac{\text { Pakistan }}{(4)}$ \\
\hline \multirow{2}{*}{ Next Birth Interval (Yrs) } & -0.0043 & -0.0029 & 0.0026 & -0.0054 \\
\hline & {$[0.0022]$} & {$[0.0011]$} & {$[0.0041]$} & {$[0.0039]$} \\
\hline \multirow{2}{*}{ \# Older Siblings } & 0.0053 & -0.0054 & -0.0111 & 0.0007 \\
\hline & [0.0049] & [0.0021] & [0.0070] & [0.0063] \\
\hline \multirow{2}{*}{ \# Older Brothers } & -0.0035 & 0.0091 & 0.0114 & -0.0044 \\
\hline & [0.0063] & [0.0030] & [0.0095] & [0.0088] \\
\hline \multirow[t]{2}{*}{ Mom's Age } & -0.0011 & 0.0008 & -0.0003 & 0.0014 \\
\hline & [0.0015] & [0.0006] & [0.0019] & [0.0019] \\
\hline \multirow{2}{*}{$\begin{array}{l}\text { Mom's Highest } \\
\text { Grade }\end{array}$} & 0.0004 & -0.0008 & 0.0002 & 0.0019 \\
\hline & [0.0018] & [0.0006] & {$[0.0032]$} & {$[0.0024]$} \\
\hline \multirow{2}{*}{$\begin{array}{l}\text { Dad's Highest } \\
\text { Grade }\end{array}$} & 0.0002 & -0.0011 & -0.0014 & -0.0005 \\
\hline & [0.0012] & {$[0.0005]$} & {$[0.0017]$} & {$[0.0015]$} \\
\hline Joint F-test $p$-value & 0.51 & $<0.01$ & 0.59 & 0.76 \\
\hline \multicolumn{5}{|c|}{$\begin{array}{lcccc}\text { Number of Obs. } & 14,650 & 77,589 & 7,542 & 6,211 \\
\text { Notes: OLS estimates. Brackets contain standard errors clustered at the PSU-level. Samples inclu }\end{array}$} \\
\hline $\begin{array}{l}\text { Notes: OLS estimates. B } \\
\text { surviving women with } \\
\text { current and next births a } \\
\text { maternal region of resid } \\
\text { cients reported in the } t \\
\text { sources are listed in App }\end{array}$ & kets contain st & errors clus & the PSU-le & $\begin{array}{l}\text { iples inclu } \\
\text { ith singlet } \\
\text { survey ye } \\
\text { o the coe } \\
\text { alues.) D }\end{array}$ \\
\hline
\end{tabular}


Appendix Table 4

Predictors of Next-Oldest Sisters, Women 15-24, Pooled Data

\begin{tabular}{lcc}
\hline & Coef. & S.E. \\
\hline \# Siblings Born Before Last & 0.012 & {$[0.002]$} \\
\# Brothers Born Before Last & -0.015 & {$[0.003]$} \\
Last Birth Interval & -0.021 & {$[0.001]$} \\
Mother's Age & 0.0012 & {$[0.0004]$} \\
Mother's Education & 0.0018 & {$[0.0006]$} \\
Father's Education & $-2 * 10^{-5}$ & {$[0.0005]$} \\
Rural & 0.005 & {$[0.004]$} \\
Year of Birth & 0.0011 & {$[0.0003]$} \\
\hline Notes: OLS Estimates. N = 83,330. The table reports a single regression in which the dependent \\
variable equals 1 for a next-oldest sister, 0 for a next-oldest brother. The sample includes all women \\
in the pooled Fertility History data with at least one older sister. Brackets contain standard errors \\
clustered at the PSU-level. Samples include girls with at least one ever-born older sibling. Only \\
observations with singleton current and last births are included. Data sources are listed in Appendix \\
Table 1.
\end{tabular}


Appendix Table 5

Next-Youngest Sister Effects on Female Outcomes in Childhood

\begin{tabular}{|c|c|c|c|c|}
\hline & $\begin{array}{c}\text { Bangladesh } \\
(1)\end{array}$ & $\begin{array}{c}\text { India } \\
(2) \\
\end{array}$ & $\begin{array}{l}\text { Nepal } \\
(3)\end{array}$ & $\begin{array}{c}\text { Pakistan } \\
(4)\end{array}$ \\
\hline \multicolumn{5}{|c|}{ A. Under-5 Mortality, All Births within 25 Years of Survey } \\
\hline Younger Sister & $\begin{array}{c}0.007 \\
{[0.003]}\end{array}$ & $\begin{array}{c}0.004 \\
{[0.001]}\end{array}$ & $\begin{array}{c}0.002 \\
{[0.004]}\end{array}$ & $\begin{array}{l}-0.003 \\
{[0.004]}\end{array}$ \\
\hline $\begin{array}{l}\text { Mean Among Girls } \\
\text { w/ a Younger Brother }\end{array}$ & 0.15 & 0.12 & 0.15 & 0.10 \\
\hline Number of Obs. & 46,946 & 246,215 & 27,064 & 23,059 \\
\hline \multicolumn{5}{|c|}{ B. Height-for-Age Z-scores, Ages 2-4 } \\
\hline Younger Sister & $\begin{array}{l}-0.005 \\
{[0.065]}\end{array}$ & $\begin{array}{c}0.005 \\
{[0.040]}\end{array}$ & $\begin{array}{l}-0.082 \\
{[0.064]}\end{array}$ & $\begin{array}{c}0.157 \\
{[0.157]}\end{array}$ \\
\hline $\begin{array}{l}\text { Mean Among Girls } \\
\text { w/ a Younger Brother }\end{array}$ & -2.26 & -1.82 & -2.29 & -2.50 \\
\hline Number of Obs. & 1,993 & 5,429 & 1,594 & 657 \\
\hline \multicolumn{5}{|c|}{ C. Weight-for-Height Z-scores, Ages 2-4 } \\
\hline Younger Sister & $\begin{array}{l}-0.098 \\
{[0.041]}\end{array}$ & $\begin{array}{l}-0.024 \\
{[0.028]}\end{array}$ & $\begin{array}{c}0.015 \\
{[0.042]}\end{array}$ & $\begin{array}{c}0.121 \\
{[0.089]}\end{array}$ \\
\hline $\begin{array}{l}\text { Mean Among Girls } \\
\text { w/ a Younger Brother }\end{array}$ & -0.94 & -0.95 & -0.83 & -0.40 \\
\hline Number of Obs. & 1,993 & 5,429 & 1,594 & 657 \\
\hline \multicolumn{5}{|c|}{ D. School Attendance, Ages 5-9 } \\
\hline Younger Sister & $\begin{array}{c}0.014 \\
{[0.009]}\end{array}$ & $\begin{array}{c}0.002 \\
{[0.006]}\end{array}$ & $\begin{array}{l}-0.005 \\
{[0.013]}\end{array}$ & $\begin{array}{l}-0.007 \\
{[0.016]}\end{array}$ \\
\hline $\begin{array}{l}\text { Mean Among Girls } \\
\text { w/ a Younger Brother }\end{array}$ & 0.81 & 0.50 & 0.70 & 0.58 \\
\hline Number of Obs. & 5,364 & 16,512 & 4,171 & 3,373 \\
\hline
\end{tabular}

Notes: OLS estimates. Brackets contain standard errors clustered at the PSU-level. Samples include girls with at least one ever-born younger sibling. Only observations with singleton current and next births are included. All regressions include fixed effects for age, mother's region of residence, survey year, and the exact composition of older siblings by birth order and sex. Regressions also control for spacing from the previous birth, maternal and paternal educational attainment, maternal age, religion, and rural residence. Data sources are listed in Appendix Table 1. 